\title{
OS PRONOMES PESSOAIS E A EXPRESSÃO DO OBJETO INDIRETO NO GALEGO-PORTUGUÊS MEDIEVAL E NO GALEGO CONTEMPORÂNEO: APROXIMAÇÃO CONTRASTIVA
}

(Personal pronouns and expression of Indirect Object in Medieval Galician-Portuguese language and in contemporary Galician language: a contrastive approach)

\section{Xosé Manuel Sánchez Rei* \\ Universidade da Coruña}

\begin{abstract}
Personal pronouns in Galician deal with various grammatical responsibilities. One of them is the expression of Indirect Objet (IO) through several structures, among which we can find nominal phrases too. The objective of this work is to develop an approach to medieval Galician-Portuguese and modern Galician to see what changes occurred in the scope of the personal pronouns and in the expression of the IO between both periods of time.
\end{abstract}

Keywords: Clitic Pronouns; Indirect Objet; Syntax; Medieval Galician-Portuguese; Modern Galician.

Resumo: Os pronomes pessoais no Galego ocupam-se de várias responsabilidades gramaticais. Uma delas é a expressão do Objeto Indireto (OI) mediante diversas estruturas, entre as quais podemos achar também frases nominais. $\mathrm{O}$ objetivo deste trabalho é desenvolver uma aproximação ao Galego-Português medieval e ao Galego moderno para ver quais mudanças têm acontecido no âmbito dos pronomes pessoais e na expressão do OI entre ambos os períodos de tempo.

\footnotetext{
* Dirección para correspondencia / Endereço para correspondência: Xosé Manuel Sánchez Rei. Departamento de Letras. Faculdade de Filologia. Universidade da Corunha. Campus da Zapateira. Rua Lisboa, 7. 15071 Corunha (sanrei@udc.gal).

O presente trabalho foi desenvolvido no marco do projeto de investigação FFI2015-63523-P, financiado pelo "Ministerio de Economía y Competitividad" do Estado espanhol. O autor quer agradecer os atenciosos comentários formulados pelas pessoas que amavelmente leram as primeiras versões deste texto, os quais contribuíram com muito para o melhorarem.
} 
Palavras chave: Pronomes cliticos; Objeto indireto; Galego-português medieval; Galego moderno.

\section{Introdução}

No sistema linguístico galego-português, como vem assinalando a tradição gramatical já desde os tempos de Fernão de Oliveira, os pronomes convencionalmente conhecidos como "pessoais" singularizam-se a respeito dos restantes paradigmas por possuírem restos do sistema declinacional latino ${ }^{1}$, isto é, por preservarem diversas formas flexionais já perdidas nos nomes. Também se identificam por se organizarem em dois inventários de formas, um para as tónicas e outro para as átonas. Justamente estas últimas, chamadas "pronomes clíticos" ou apenas "clíticos" $(\mathrm{Cl})$, constituem morfemas que, em termos predicativo-argumentais, sofrem habitualmente o controlo do verbo e dependem fonética e sintaticamente dele ${ }^{2}$, coadjuvando assim na sua constituição e a expandirem-no.

Por tal motivo, os $\mathrm{Cl}$ circundam o verbo: como colocação normal ou não marcada, quando menos na Galiza e em Portugal, situam-se em posições pós-nucleares (ênclise) em cláusulas enunciativas afirmativas; e, às vezes, noutros tipos de unidades clausulares e devido a condicionantes de variada índole -nomeadamente morfossintáticos e/ou relacionados com as estruturas informativas-, dispõem-se em colocações pré-nucleares (próclise). Isto torna-se congruente com o facto de serem denominados nalguns estudos clássicos de romanística, pronomes "conjuntos", relativamente a uma forma verbal (Iordan; Manoliu 1989: 285-90), opostos às "variantes absolutas" ( $\mathrm{eu}, \mathrm{tu}$, etc.); e também explica que hodiernamente o verbo seja percebido como o "hospedeiro" deles ou a sua "palavra hospedeira" (Martins 2013: 2231; Bogard 2015: 5-6). Ao passo, há autores que mantêm que os $\mathrm{Cl}$ estão hoje gramaticalizados como afixos verbais e não faltam romanistas que se têm referido a eles em termos de "conjugação objetiva", conforme Posner (1998: 216), lembrando assim o seu tratamento por Heger (1967) na segunda metade do pasado século para o francês e o castelhano. Esta singularidade não teria a sua importância se não pensássemos em que os modernos morfemas verbais de número e pessoa foram, nalgum tempo, elementos pronominais que terminaram por se aglutinar ao verbo para marcarem um determinado tipo de concordância com o SUJ.

Noutra ordem de ideias, as funções que os $\mathrm{Cl}$ são capazes de desenvolver atualmente no galego, de acordo com o exposto nas modernas descrições gramaticais (cf. Álvarez

1 Assim o indicava o autor na sua Grammatica da Lingoagem Portuguesa de 1536: "E contudo nós também temos casos em três pronomes, os quais são eu, me, mi, tu, $t i$, se, si" (Oliveira 2000: 150).

2 Note-se que, na realidade, o conceito de "clítico" excede o âmbito pronominal, pois clítica é toda a palavra que carece de acento fonológico e que precisa de se vincular a um outro elemento tónico para poder pronunciar-se num texto oral. Cf. Mateus et al. (2003: 828-829), obra em que, baseando-se em autores como Zwicky ou Vigário, se diferenciam os "clíticos especiais" (= formas átonas do pronome pessoal) dos "clíticos simples" (= artigos e preposições). Por outra parte, a análise dos elementos clíticos abrange várias perspetivas de estudo, como são a fonológica, a morfológica e a sintática (cf. Spencer; Luís 2012), suscetíveis de se abordarem tanto diacrónica como sincronicamente com diversos marcos teóricos; prova de tudo isso é a notável bibliografia existente ao respeito, recolhida parcialmente desde finais do século XIX até à década de 90 do século XX em Nevis et al. (1994). 
Os pronomes pessoais e a expressão do objeto indireto no galego-português medieval e no galego contemporâneo: aproximação contrastiva

I Xove 2002: 539-570; Hermida Gulías 2004: 77-94; Freixeiro Mato 2006, II: 122-185, 195-198; etc.), enformam um conjunto de responsabilidades muito variadas, tanto no domínio clausular quanto no textual ou discursivo:

I. Desempenham funções sintáticas (Atr, OD, OI) no sentido de representarem em anáfora ou em catáfora um nome, uma frase, uma cláusula ou mesmo um texto inteiro. Por isto, dentro dos mecanismos textuais de coesão referencial, os $\mathrm{Cl}$ e o resto dos pronomes viram unidades de uma relevância notável, já que agilizam o ritmo discursivo do texto ao fazerem com que não haja que reiterar de modo cansativo certas unidades frásicas ou clausulares.

II. Com outro tipo de encomendas, marcam, nas estruturas de redobro do $\mathrm{Cl}$, um tipo de concordância entre o verbo e alguns dos seus argumentos (OD, OI) (cf. Duarte / Matos 1984; García-Miguel 1991; Cidrás Escáneo 1992; etc.), o que redunda no seu caráter morfemático a respeito daquele ${ }^{3}$ e fortalece a impressão de que os pronomes átonos têm uma responsabilidade sintático-funcional menos vinculada à expressão do OI. Vale a pena salientarmos que as estruturas de redobro do $\mathrm{Cl}$ se acham preferencialmente na România no âmbito galego-português e no espanhol, segundo salienta Gonçalves (2015: 58): "Among Romance langauges, the occurrence of clitic-doubling is not a generalized property. In fact, while Spanish and EP [=European Portuguese] allow clitic-doubling, French and Italian do not"4. A este respeito, tem-se debatido sobre qual dos dois pronomes, o átono ou o tónico, é o responsável por desenvolver a função sintática, como sintetiza Company Company (2006: 491):

Un último problema teórico relacionado con el OI [= Objeto Indireto $]$ es, en los casos de duplicación del OI, el determinar cuál elemento es el constituyente regido por el verbo, si el clítico o la FP [= Frase Preposicional], y cuál es el elemento que opera como copia. El hecho de que en español moderno ciertas construciones de OI, especialmente aquellas que involucran pronombres personales o nombres propios y determinados tipos de verbos requieran duplicación obligatoria, sin que pueda aparecer la FP sola [...], ha motivado que en algunos trabajos se asigne el papel del OI al clítico y el papel de copia a la FP [...]. Sin embargo, el mayor peso estructural de la FP y el hecho de que un buen número de construcciones de OI pueda aparecer con la sola FP sin necesidad de duplicación han propiciado que otros estudiosos consideren la FP como el verdadero constituyente OI que entabla relaciones con el verbo, y el clítico como la copia de aquella.

Como quer que seja, a prova de os pronomes átonos funcionarem de preferência como morfemas verbais é o facto de nunca poderem aparecer empregues como elemen-

3 Pontos de vista não coincidentes são, entre outros, o de Almeida (1999: 426), que assinala que as formas tónicas do pronome em Eu me considero a mim ou Feriu-se a si correspondem a "repetições pleonásticas" ou "reforços dos objetos diretos", ou o de Martins (2000: 158-159), a qual diz que nestas estruturas há "dois termos exercendo uma mesma função".

4 Também se documentam, contudo, noutras línguas ou variedades românicas, como o catalão ou o italiano dialetal. Cf., neste sentido, Pineda (2013) ou Cordin (1993). 
tos únicos numa cláusula, o que não acontece com os oblíquos tónicos, que sim possuem esta capacidade (por exemplo, funcionarem como uma resposta: -Onte vímoste na facultade - $\boldsymbol{A} \mathbf{m i n}$ ? -Si, a ti I -Onte vímoste na facultade -*Me? -*Si, te; cf. Mateus et al. 2003: 829)

III. São capazes de se comportarem como SUJ de um infinitivo em construções causativas ou hiper-transitivas, na terminologia de Moreno Cabrera (1987: 48 e ss.). A opção do emprego do acusativo, mais típica da tradição galego-portuguesa, também serve para explicitar o género desse SUJ (cf. Mandeina sair = Mandei que ela saíse vs. Mandeille saír = Mandei que ellela saíse; cf., sobre estas responsabilidades sintáticas, Regueira 1998; Sousa 2012).

IV. Com verbos tradicionalmente considerados intransitivos, o acusativo pode ocorrer como um índice funcional de um SUJ apresentado em anáfora ou em catáfora, o que volta a ponderar a relevância dos $\mathrm{Cl}$ como importantes ferramentas na coesão textual $^{6}$ (cf. -Onde están os rapaces? - Ai os están, non os ves?; Alí as veñen, as túas amigas, no carro; cf. Cidrás Escáneo 1992; Álvarez 2015).

V. A continuarmos na esfera sintática, a presença / ausência dos $\mathrm{Cl}$ reflexos ou o uso deles com determinados verbos no galego atual proporciona-nos várias informações: assim, semanticamente, detetam-se diferenças nalguns pares de verbos, como nos casos de afogar vs. afogarse ('morrer por asfíxia involuntariamente vs. 'enforcar-se'), ocorrer vs. ocorrerse ('acontecer' vs. 'ter uma ideia'), etc. Ao mesmo tempo, a combinação com o acusativo ou dativo é capaz de implicar alterações no significado (cf. $O$ pai pegoulle sen avisar $=O$ pai deu-lhe uma pancada $\ldots ;$ O pai pegouno sen avisar $=O$ pai colou-o $\ldots$; Valeuche o martelo? = Serviu-te...?; Valeute como un verdadeiro amigo $=$ Ajudou-te...; etc.; cf. Freixeiro Mato 2006, II: 156-159).

VI. Finalmente, na confluência do eixo sintático com o pragmático-discursivo, os $\mathrm{Cl}$ de dativo podem marcar e envolver a pessoa que age como recetora no ato ilocutório e mesmo assinalarem o tratamento que se tiver com ela (cortês: lle e lles / não cortês: che e vos); isto dá-se com o chamado "dativo de solidariedade", uma singularidade do galego se comparado com outras línguas românicas, quando menos nas suas variedades standardizadas (cf. O cinema está aí abaixo / O cinema estáchevos aí abaixo; cf. Álvarez Blanco 1997). Em segundo lugar, às vezes deixam transparecer certa sorte de interesse ou implicação afetivo-emocional no desenvolvimento da predicação linguística por parte do emissor através do conhecido "dativo de interesse" (cf. Este rapaz non estuda nada / Este rapaz non me estuda nada). E em terceiro lugar, permitem ser utilizados com

5 Se não se indicar explicitamente a procedência de um corpus, os exemplos galegos são de elaboração própria e estão citados na variedade padrão.

6 Freixeiro Mato (2013: 125), a assinalar alguns traços destes usos do clítico, pondera a sua "grande" rendibilidade expressiva por causa da "súa plasticidade". Tal utilização, originariamente dialetal, acabou por penetrar na linguagem literária galega, na qual já se deteta em finais do século XVII, como na Contenda dos labradores de Caldelas, de 1671 (cf.: Rapaces, mulleres, vellos, / eilos vén nunha bandada, SEI: 90) ou nalgún romance das Festas Minervais de 1697 (cf.: Ora, eilo vai, meus fidalgos, I os prólojos encurtemos, SEI: 35), etc. E dos textos literários e da oralidade dialetal contemporânea conseguiu projetar-se em textos jornalísticos: numa entrevista aparecida no suplemento "Fóra de serie" do semanário Sermos Galiza (21/06/2018, nº 301: 4-5,), pode ler-se: "Quentin Tarantino tampouco estudou audiovisuais e aí o está". 
valores semânticos que exprimem matizes referenciais de posse mediante do "dativo possessivo" (cf. Morreu a súa avoa / Morreulle a avoa). Nestes três casos, os dativos não argumentais exemplificam amostras de "atantes exteriores" ao marco predicativo do verbo ${ }^{7}$.

\section{Objetivos, metodologia e fontes}

Vistas as principais responsabilidades dos $\mathrm{Cl}$ e já agora nos centrando nas esferas sintáticas recolhidas nas alíneas (I) e (II) que se acabam de assinalar, pretendemos fazer no presente trabalho um achegamento contrastivo às estruturas em que aparece a função de OI. Para isso, a comparação será feita entre essas construções na língua medieval e no galego moderno através de seis estruturas detetadas (cf. 3.2), nas quais a presença dos pronomes pessoais átonos e oblíquos tónicos protagoniza um papel fundamental; igualmente, consideraremos nalguns casos particulares o conhecido como Galego Médio, dado que é nesta época que se verificam certas transformações entre a língua medieval e a contemporânea. A nossa finalidade elementar, portanto, consistirá em darmos conta (i) daquelas construções que conseguiram manter-se sem praticamente experimentarem alterações; (ii) das que, com efeito, sofreram mudanças quanto à sua rendibilidade, ora acrescentando-a, ora a diminuírem-na; e (iii) daqueloutras que desapareceram no trânsito da língua antiga à dos nossos dias.

No que diz respeito às fontes, foram analisados, para o caso dos tempos medievais, textos provenientes de diversos géneros e com desiguais finalidades artísticas (lírica, prosa literária e prosa notarial), procedentes, de preferência, da atual Galiza, o que harmoniza a continuidade no espaço relativamente a tais obras. Ao mesmo tempo, tivemos em conta para a atualidade documentos orais disponibilizados na rede que abrangem todo o território. Tambem se acudiu a textos de origem tradicional, já que, apesar de nem sempre corresponderem com exatidão ao estádio da língua do momento em que foram coligidos, podem ser utilizados para proporcionarem informação sobre o galego dialetal, popular ou rural e em épocas em que não havia registos orais (cf. Mariño Paz 2017: 99); neste sentido, de maneira pontual, manejamos textos provenientes da literatura anónima do norte de Portugal, já que, às vezes, fornecem amostras de construções infrequentes no português comum, mas habituais no galego. Quanto à documentação existente para os séculos do Galego Médio (XVI-XVIII), dado que foi o transcendental período em que se produzem ou em que assentam as mudanças que corroboram as diferenças entre a língua da Idade Média e a moderna, e dada também a escassez de obras escritas ou conservadas desse tempo, operou-se com o maior número de textos possíveis. Em síntese, eis a relação das fontes documentais utilizadas:

7 Cf. Vilela (1999: 335). Estes clíticos têm-se denominado noutros trabalhos "circunstantes" ou "dativos livres" (Vilela 1992: 118, 121-125), "dativos quase-argumentais" (Mateus et al. 2003: 839-40), "dativos não argumentais" (Pita Rubido 2006; Miguel et al. 2011), etc. 


\section{a) Idade Média}

CSI = SOUTO CABO, José António (ed.) (2001): Rui Vasques, Crónica de Santa María de Íria. Sada-A Coruña: Ediciós do Castro.

CT = LORENZO, Ramón (ed.) (1985): Crónica Troiana. A Coruña: Fundación Barrié de la Maza.

DGP = SOUTO CABO, José António (ed.) (2008): Documentos GalegoPortugueses dos Séculos XII e XIII. Monografia 5 da Revista Galega de Filoloxía. A Coruña: Área de Filoloxía Galega e Portuguesa da Universidade da Coruña.

GE = MARTÍNEZ-LÓPEZ, Ramón (ed.) (1963): General Estoria. Oviedo: Universidad de Oviedo.

HGP = MAIA, C. de Azevedo (ed.) (1997) [1986]: História do Galego-Português. Lisboa: Fundação Calouste Gulbenkian / Junta Nacional para a Investigação Científica e Tecnológica.

LP = BREA, Mercedes (coord.) (1996): Lírica Profana Galego-Portuguesa. Santiago de Compostela: Centro Ramón Piñeiro.

LTM = LORENZO GRANDÍN, Pilar; SOUTO CABO, José António (coords.) (2001): Livro de Tristan e Livro de Merlin. Santiago de Compostela: Centro Ramón Piñeiro.

MS = PENSADO, José Luís (ed.) (1958): Miragres de Santiago. Anejo LXVIII da Revista de Filología Española. Madrid: CSIC.

SM = ZAPICO BARBEITO, María Pilar (ed.) (2005): Colección Diplomática do Mosteiro de Santiago de Mens. Noia: Toxosoutos.

UC = FERREIRO, Manuel (dir.) (2018-): Universo Cantigas. Edición Crítica da Poesía Medieval Galego-Portuguesa. A Coruña: Universidade da Coruña. Disponível em http://universocantigas.gal. [última consulta: 06/02/2019].

\section{b) Galego Médio}

C = MARIÑO PAZ, Ramón (ed.) (1996): Fr. Martín Sarmiento, Coloquio de Vintecatro Galegos Rústicos. Santiago de Compostela: Consello da Cultura Galega.

CDE = FERNÁNDEZ SALGADO, Xosé A. (ed.) (2017): Cincuenta Décimas contra Don Diego Zernadas. Santiago de Compostela: Laiovento.

DAB = ÁLVAREZ BLANCO, Rosario; RODRÍGUEZ MONTEDERRAMO, Xosé Luís (2002): "O Diálogo de Alberte e Bieito. Dramaturxia, elites letradas e escrita do galego en fins do século XVI", Boletín da Real Academia Galega. Vol. 363: 241-311.

HDS = SOUTO CABO, José António (ed.) (2007): A História de Don Servando. Sada-A Coruña: Ediciós do Castro.

HSI = ARIAS, Bieito; NOIA, Camiño (eds.) (2011): Pedro de Otero Romero y Torres, Historia da Santa Igrexa de Iria. Vigo: Universidade de Vigo.

PG = BLANCO, Domingo (ed.) (1992): A Poesía Popular en Galicia (17451885 ). Vol. I, pp. 118-144. Vigo: Xerais.

RU = MARIÑO PAZ, Ramón et al. (eds.) (2012): O Romance da Urca de Santo Antón (1777). A Coruña: Fundación Barrié de la Maza.

SEI = FREIXEIRO MATO, Xosé Ramón (ed.) (1996): A Nosa Literatura . Vol. VII. Os Séculos Escuros e a Ilustración Galega. Vigo: A Nosa Terra. 
Os pronomes pessoais e a expressão do objeto indireto no galego-português medieval e no galego contemporâneo: aproximação contrastiva

\section{c) Época contemporânea}

AGO = FERNÁNDEZ REI, Francisco (dir.) (2010-): Arquivo do Galego Oral. Santiago de Compostela: Instituto da Lingua Galega. Disponível em http://ilg.usc. es/ago/ [última consulta: 25/04/2019].

ANF = FERNÁNDEZ REI, Francisco; HERMIDA GULÍAS, Carme (eds.) (2003) [1996]: A Nosa Fala. Bloques e Áreas Lingüísticas do Galego. Santiago de Compostela: Consello da Cultura Galega. Disponível em http://consellodacultura. gal/arquivos/asg/anosafala.php [última consulta: 26/04/2019].

CPG = PÉREZ BALLESTEROS, José (ed.) (1979) [1885-86]: Cancionero Popular Gallego. Madrid: Akal.

LPG = SACO CID, José Luís (ed.) (1987): Literatura Popular de Galicia. Ourense: Deputación Provincial.

RT = FONTES, Manuel da Costa (ed.) (1987): Romanceiro da Província de Trásos-Montes (Distrito de Bragança). Coimbra: Universidade de Coimbra.

\section{A situação da língua medieval}

\subsection{As formas}

Antes de começarmos a assinalar as construções em que os $\mathrm{Cl}$ e os pronomes tónicos oblíquos têm protagonismo, pensamos que não está de mais reproduzirmos as formas com que aparecem nos textos, pois, no seu conjunto, não coincidem com os paradigmas atuais, quando menos na variedade standard do galego (c.f. 4.1) e do português europeu (PE) e brasileiro (PB). Seguimos o exposto em Williams (1975: 152-59), Nunes (1989: 236-42), Silva (1989: 212-17) ou Ferreiro (1999: 248-53):

\footnotetext{
8 Empregámos em AGO as versões transcritas na variedade standardizada e em ANF adaptámos unicamente a ortografia utilizada nesses textos, conservando-lhes todos os traços gramaticais e lexicais. Em ambos os corpora não tivemos em conta os dativos sintática e semanticamente não argumentais.
} 
Tábua 1. Formas dos pronomes pessoais clíticos na época medieval

\begin{tabular}{|c|c|c|c|c|c|c|c|}
\hline Pessoa & & \multicolumn{4}{|c|}{ Pronomes não reflexos } & \multirow{2}{*}{\multicolumn{2}{|c|}{$\begin{array}{c}\text { Pronomes } \\
\text { reflexos }\end{array}$}} \\
\hline & \multicolumn{2}{|c|}{ Acusativo } & \multicolumn{2}{|c|}{ Dativo } & \multirow[b]{2}{*}{$\begin{array}{c}\text { Formas } \\
\text { gerais }\end{array}$} & & \\
\hline & $\begin{array}{c}\text { Formas } \\
\text { gerais }\end{array}$ & $\begin{array}{c}\text { Alomorfias } \\
\text { e/ou alografias }\end{array}$ & $\begin{array}{c}\text { Formas } \\
\text { gerais }\end{array}$ & $\begin{array}{c}\text { Alomorfias } \\
\text { e/ou alografias }\end{array}$ & & $\begin{array}{c}\text { Alomorfias } \\
\text { e/ou alografias }\end{array}$ & \\
\hline \multicolumn{2}{|l|}{ P1 } & me & $m i$ & me & $m i$ & me & $m i$ \\
\hline \multicolumn{2}{|l|}{ P2 } & te & $t i$ & te, che $^{9}$ & $t i, c h i$ & te & $t i$ \\
\hline \multirow[t]{2}{*}{ P3 } & $\mathrm{M}$ & $O$ & $u, n o, l o$ & \multirow{2}{*}{$\begin{array}{l}\text { lhe, } \\
\text { lle }\end{array}$} & \multirow{2}{*}{$\begin{array}{r}\text { lhi, } \\
\text { lli }\end{array}$} & \multirow{2}{*}{$\begin{array}{l}\text { se, } \\
x e^{10}\end{array}$} & \multirow{2}{*}{$\begin{array}{l}s i \\
x i\end{array}$} \\
\hline & $\mathrm{F}$ & $a$ & la, na & & & & \\
\hline \multicolumn{2}{|l|}{ P4 } & nos & nus & nos & $n u s$ & nos & nus \\
\hline \multicolumn{2}{|l|}{ P5 } & vos & vus & vos & vus & vos & $v u s$ \\
\hline \multirow[t]{2}{*}{ P6 } & $\mathrm{M}$ & os & us, nos, los, & \multirow[t]{2}{*}{ lhes, lles } & \multirow{2}{*}{$\begin{array}{c}\text { lhis, llis, } \\
\text { lhe, lli }\end{array}$} & se, & \multirow{2}{*}{$\begin{array}{l}\text { si, } \\
x i\end{array}$} \\
\hline & $\mathrm{F}$ & as & las, nas & & & xe & \\
\hline
\end{tabular}

Os elementos recolhidos neste quadro solicitam umas palavras. Em primeiro lugar, ao falarmos em $\mathrm{Cl}$, temos de fazer referência (i) à mudança que supus, no percurso latim > romance, a passagem de um acento musical para um outro baseado na maior força articulatória e (ii) à datação em que as formas pronominais hoje átonas perderam o acento fonológico. Na época literária latina vigorava um acento de caráter melódico consistente numa elevação da voz, que iria evoluindo para um dinâmico ou de intensidade, segundo se ia perdendo a distinção longa/breve no vocalismo (Ē/Ě, ō/ŏ, etc.) e conforme ia ganhando relevância funcional a oposição fechada/aberta (e/ع, o/s, etc.). Por volta dos séculos III-IV da nossa era, que correspondem linguisticamente ao latim tardio, podemos já pensar num acento de intensidade no sentido em que se desenvolveria nas posteriores línguas e variedades românicas: formas registadas naquela época, como articlus (<ARTiCUlus), SPECLUM (<SPECUlum), etc. no Appendix Probi (cf. Coutinho 1976: 37 e ss.; Väänänen 1988: 330), nas quais se produz a síncope da vogal átona, parecem ser indícios desta mudança acentual, pois dificilmente numa sílaba tónica têm lugar essas modificações. Por isso, em se podendo documentar ARTiclus ou SPECLUM, a sugerirem uma acentuação de intensidade, provavelmente também começassem a existir as formas átonas do pronome pessoal. Naquela altura, pois, pôde ter-se iniciado o desdobramento da classe pronominal em duas séries, a tónica e a átona, a qual conseguiria consolidar-se nos seguintes séculos dando origem aos paradigmas de pronomes átonos (cf. Wanner 1987: 57-66, 67 e ss; Luis / Kaisser 2016; etc.).

Como segunda questão, e dando por assente que na época medieval a diferenciação entre formas tónicas e átonas do pronome corresponderia a uma situação coincidente

$9 \quad$ Ferreiro (1999: 249) explica o aparecimento do pronome che a indicar que "parte da palatalización da inicialmente forma única $t e$, cando precedida de $-s$ (normalmente dunha forma verbal) e seguida de vogal, especialmente as formas de pronome persoal de terceira persoa $o(s), a(s):-\mathrm{s}+$ te $+\mathrm{o}>\mathrm{s}$-tjo $>\mathrm{s}-\mathrm{cho}[\ldots]$; a partir de aquí, polo modelo de $m e$, te, etc., tirouse unha forma pronominal che especializada para a función de complemento indirecto".

10 Para a variante xe ou xi, com palatalização, o processo, segundo Ferreiro (1999: 252), obedeceria aos passos que se seguem: "se+a, se+o, sjo $>\mathrm{xa}$, xo, de onde se tira unha forma $x e$ que despois pode aparecer como $x i$ pola vacilación melmi, etc." 
Os pronomes pessoais e a expressão do objeto indireto no galego-português medieval e no galego contemporâneo: aproximação contrastiva

com a atual ou muito próxima dela, devemos notar a existência dos pronomes de $\mathrm{P} 1$, P2, P3 e P6 com <e > e <i possivelmente devida à flutuação da vogal átona; esta oscilação torna-se paralela à dupla atestação de $o$ e $u$, nos e nus, etc., e é justificada com facilidade pela condição inacentuada dos Cl (Williams 1975: 154). Por seu turno, a atestação das variantes no, $n a$, etc. e lo, la, etc. está explicada por motivos gramaticais, derivados de condições fonético-sintáticas (Ferreiro 1999: 250-51).

Em terceiro lugar, nos $\mathrm{Cl}$ de $\mathrm{P} 2$ achamos te e che, este último preferencialmente no período pós-trovadoresco e com maior frequência em textos setentrionais. Na maioria das falas galegas modernas, te é empregado como acusativo e reflexo (cf. Saudeite, mais non me viches; Lávaste con auga do pozo ou con auga da torneira?), ao passo que che se utiliza para o dativo (cf. Vou darche un consello), excepto nalgumas zonas ocidentais da atual província da Corunha, em que che se usa para acusativo (cf. Sempre che levei no corazón) e para dativo (cf. Empréstoche este libro se mo devolveres en dous días) (ALGa, II: 174-75; Ferreiro 1999: 248-49). Nos falares portugueses modernos, por seu turno, te é utilizado tanto para acusativo e dativo quanto para o reflexo. Porém, há algumas áreas na Galiza, nomeadamente na região do Baixo Minho, em que a única forma empregada é te para as funções de dativo e acusativo e para o reflexo (ALGa, II: 174-75; Ferreiro 1999: 248-49); ao mesmo tempo, che ainda se acha no PE literário do século XVI, pois foi utilizado por Francisco de Sá de Miranda (1491-1558) (Carvalho 1953: 81) e, no norte de Portugal, Vasconcellos (1928: 322) inclusive pôde atestar esta forma nos primórdios do século XX:

É muito notável o pronome dativo che (como em galego): dei-che, deu-che, que ouvi em Paços, em C. Laboreiro e em S. Gregório (aquí já tido por antiquado, pôstoque em uso. Informaram-me que em Melgaço se diz chibato, do verbo bater: creio se entenderá (em frase) eu che bato; guiei-ch'o jantar (preparei-te o jantar), ibidem; dei-ch'isso, que ouvi em S. Gregório. O mesmo che se ouve também em Viladreque, Chaviães, etc.

E em quarto lugar, relativamente à grafia $<\mathrm{lh}>$ para as formas de dativo de $\mathrm{P} 3$ e $\mathrm{P} 6$, e pela transcendência que depois chegou a ter internacionalmente na identificação da ortografia lusitana face à oficial galega da atualidade, convém lembrarmos que em textos da Galiza a mais utilizada foi <1l>, embora também se tenha constância de outros usos gráficos ${ }^{11}$. Em confronto, a língua escrita nos territórios portugueses já desde finais do século XIII optou por representar esse fonema palatal com o antecitado dígrafo $<\mathrm{lh}>$ por causa da vontade do rei Afonso III (1210-1279) de a importar desde tradições ortográficas ultra-pirenaicas ${ }^{12}$, bem como $<$ nh $>$ para o subsequente fonema nasal pa-

11 Minoritariamente, há documentações portuguesas das zonas setentrionais, mesmo do século XV, em que se deteta o dígrafo <1l> (moller, HGP: 286, datado em 1401; valla, HGP: 287, 1401; moller, HGP: 290, 1407; etc.), enquanto também há amostras de textos galegos até de épocas posteriores (s. XVIII) em que se atesta $<$ lh $>$ (filho, RU: 24; milhor, RU: 25; lhe, RU: 27; velhas e velhos, C: 119; etc.).

12 Tradicionalmente tem-se explicado desde o provençal, ainda que o estudo de Ramos (2013), que proporciona exemplos de zonas periféricas da România (Apúlia, Portugal, Valónia), sugira uma interpretação poligenética para o aparecimento dessas grafias em várias línguas e dialetos românicos. 
latal. Questões igualmente gráficas são os casos de variantes como $m y, t y$, sy, etc., que optamos, dada a sua única natureza alográfica sem ulteriores repercussões fonéticas, por as não incluirmos na anterior Tábua 1 .

\subsection{As construções}

Relativamente às estruturas, achamos várias possibilidades para o caso de verbos bivalentes (SUJ + OD, SUJ + OI) e trivalentes (SUJ + OD + OI) (tipo amar, arrendar, dar, dizer, enviar, escrever, guardar, mandar, matar, lançar, outorgar, peitar, etc.). Dado que a transitividade é um comportamento sintático variável conforme ficou exposto no clássico trabalho de Blinkenberg (1969: 45), alguns destes verbos apresentavam certas regências de argumentos nem sempre equivalentes à época atual, as quais, quando não coincidentes com a moderna, não foram tidas em conta.

\subsubsection{Estrutura 1: V + obl. tónico}

A primeira construção é aquela em que aparecem as "formas do oblíquo puras (sem a)" (Huber 1986: 174), quer dizer, sem preposição e sem o reforço do Cl. Isto passa-se com muita frequência com o pronome mim (Ferreiro 1999: 246), embora também se possam atestar outras formas pronominais. Recentemente, Monteagudo Romero (2019: 102103), a se basar nos cancioneiros trovadorescos, tem sublinhado para estas construções de "dativo libre" uma relativa vigência no período pré-literário, para depois cair "na obsolescencia xa na segunda metade do século XIII". Em ocasiões, como se observa em (1ef), o $\mathrm{Cl}$ de dativo aparece com verbos de movimento, de forma que não equivale à função de OI; neste sentido, Monteagudo Romero também salienta como o dativo corresponde às vezes prototipicamente não a um OI, mas a um dativo de interesse:

(1) a. ca destas coitas qual xe quer / m'é min mui grave d'endurar (UC, Nuno Fernandez Torneol, $2^{\circ}$ quartel do s. XIII) $)^{13}$

b. -Abril Perez, os olhos enganar / van omen das cousas que gran ben quer: / assi fezeron vós, a meu cuidar (UC, Bernal de Bonaval \& Abril Perez, $1^{\mathrm{a}}$ metade do s. XIII)

c. non lle quero ja sofrer ren / nen quer'eu ela consentir / quanto mal me faz (UC, Joan Soarez Somesso, $1^{\circ}$ quartel do s. XIII)

d. Min fez meter meu coraçon / en amar tal senhor que non / sei osmar guisa nen razon (UC, Fernan Rodrigues de Calheiros, $1^{\circ}$ quartel do s. XIII)

e. Ledas sejamos oj[e]-mais / e dancemos, pois nós chegou / e o Deus connosco juntou (UC, Anónimo)

13 Quando possível, marcamos o ano de composição do texto para as documentações medievais e as modernas (séculos XVI-XVIII); noutros casos, porém, só pudemos assinalar a datação de maneira aproximativa, sempre nos guiando pelos dados que figuram nas edições consultadas. Os textos orais atuais e as obras contemporâneas não levam essas indicações ao entendermos que a sua localização cronológica não apresenta problemas para se verificar. No caso da edição digital UC, incluímos o nome do poeta, já que responde à forma interna de organização. 
Os pronomes pessoais e a expressão do objeto indireto no galego-português medieval e no galego contemporâneo: aproximação contrastiva

f. mais cuid'en quanto mal min ven, / cativ', e mal dia naci! (UC, Pero Garcia Burgalês meados do s. XIII)

Saíndo por un momento do alvo do nossos objetivos, temos de assinalar que esta possibilidade de construção aparece com maior frequência em casos em que o pronome oblíquo desenvolve responsabilidades de OD. No já citado trabalho de Monteagudo Romero (2019), por exemplo, distinguem-se várias hipóteses de construção, para além de um maior número de exemplos com OD relativamente aos casos em que o pronome desempenha funções de OI. Na realidade, a ausência da preposição em tais circunstâncias parece responder à falta de fixação formal do nexo com o OD, também detetável noutras línguas e variedades românicas ${ }^{14}$. Esta situação foi mudando do ponto de vista cronológico, ao passo que também se percebem diferenças quanto ao tipo de textos; as obras medievais que manejamos facilitam-nos uns dados coniventes, no geral, com os expostos por López Martínez (1993: 221-24): em primeiro lugar, durante o século XIII, as poesias trovadorescas (LP, UC) e os documentos notariais (DGP, HGP, etc.) verificam o seu uso assistemático, em que as mais das vezes o OD ocorre sem preposição; em segundo lugar, durante o século XIV a deteção de $a$ com os pronomes oblíquos tónicos acrescenta as suas atestações; e em terceiro lugar, na seguinte centúria observamos que a presença da marca prepositiva "tende a consolidarse non só diante dos pronomes de $1^{\mathrm{a}}$ e $2^{\mathrm{a}}$ persoa, senón tamén cos de $3^{\text {a" }}$ nas palavras de López Martínez (1993: 222). Eis algumas amostras:

(2) a. deuedes uos mĩ amar bem et fielmente (HGP: 44, 1265)

b. Mha senhor, quen me vos guarda / guarda myn e faz pecado (LP, I: 103, $1^{\circ}$ quartel do s. XIV)

c. leixade min que vos quero ben (LP, I: $105,1^{\circ}$ cuartel do s. XIV)

d. Que mal matei os meus olhos e mi / que non tornei a mia senhor veer (UC, Fernan Rodrigues de Calheiros, $1^{\circ}$ quartel do s. XIII)

e. se esta batalha máis durasse matarades vós min ou eu vós (LTM: 166, $1^{\text {a }}$ metade do s. XIV)

g. os padres e as madres comiã os fillos e os fillos eles (MS: $41,1^{\circ}$ quartel do s. XV)

\subsubsection{Estrutura 2: $\mathrm{V}+a+o b l$. tónico}

Voltando já ao âmbito dos dativos, na segunda construção documenta-se o pronome tónico oblíquo introduzido pela preposição $a$ e sem o $\mathrm{Cl}$, o que resulta ser uma possibilidade muito registada. Nestes casos, em congruência com o exposto mais acima, achamos que é a FN a que desenvolve a função sintática pertinente de $\mathrm{OI}^{15}$ :

14 Cf. Fernández Soriano (2000: 1222-23), que cita o caso do castelhano medieval.

15 Houve, naquela altura, vários territórios linguísticos que conheceram estruturas equivalentes às da segunda possibilidade ( $\mathrm{V}+a+$ obl. tónico): para o caso de dialetos ibero-romances centrais, é de interesse Ariza (2009: 147), que salienta exemplos como den a mi ou vendiolas a mi. 
(3) a. Et a mĩ semella que este cõssello he leal et dereyto (CT: 525, 1373)

b. ese cõssello será mellor e mays proueytoso que o que uós cõssellades a mĩ (CT: 528, 1373)

c. outra viña de Janrozo que nos deramos a uos Martin Perez (HGP: 48, 1282)

d. A min dan preç', e non é desaguisado (LP, I: 75, c. 1240-1250)

e. -Amiga, estad[e] ora calada / um pouco, e leixad'a min dizer (LP, I: 178, finais do s. XIII-inícios do s. XIV)

f. Amor faz a min amar tal señor / mais fremosa de quantas og'eu sei (LP, I: 126, c. 1284-1289)

g. o qual uós et [o] conuento do dito moesteir a mjn destes (SM: 16, 1344)

Por outro lado, pelas caraterísticas gramaticais e textuais de determinadas tipologias de documentos, como os tabeliónicos, a adjacência do OI (exprimido através do pronome oblíquo tónico) a respeito do OD pode ver-se consideravelmente afetada mercê à intercalação de certos elementos (vocativos, aposições, frases, cláusulas, etc.). Em ocasiões, a complexa estrutura dos textos jurídico-administrativos exige a presença de recapitulações ou de repetições, tal como se aprecia em (4b-c) com a fórmula "Convém a saber" ou em (4c) com o uso desta mesma expressão e com a introdução reiterativa de "que uos damos e aforamos":

(4) a. outorgo para senpre a uos Loppo Pelaez, canbeador, morador na rua da Moeda Uella et a uossa moller Costança Uaasquez et a uossas uozes todolos herdamẽtos, casas, casares de herdades, casaes chantados, cõ todas suas pertẽẽças et dereyturas (HGP: 57, 1351)

b. damos e aforramos [sic] a uós, Gonçaluo Nouo, morrador [sic] en Uardayo, frijgisía de San Martino de Cores, et a uosa moller Maria Fernandes et a toda(s) uosa voz por en dias de vosas vidas d'anbos et por máys hũa vosa voz, a qual o postremeyro de uós nomear após súa morte, et por máis XXVIIJ anos; convén a saber: a nosa leyra d'agro Mayor (SM: 27, 1417)

c. aforamos et damos a teer et usar a vós, Joán Fernandes, morador en Beo, et a uosa moller Maria Sayoane, que presentes sodes, por en tódoslos días de uosas vidas e do máys postromeiro de uós que ficar após lo outro, vijnte et noue anos a alende depoys de uosas mortes. Conuén a saber: que uos damos et aforamos o noso formal de casa que jaz enno dito lugar de Beo (SM: 49, 1461)

\subsubsection{Estrutura 3: $\mathrm{V}+\mathrm{Cl}+a+$ obl. tónico}

Com a terceira das possibilidades dá-se a presença das formas clíticas com os pronomes tónicos oblíquos, os quais desenvolvem responsabilidades sintáticas de $\mathrm{OI}^{16}$. Nesta

16 Neste tipo de sequências pleonásticas, como se observa nos exemplos de (5a, 5c-d), são especialmente recorrentes as estruturas com interpolação pronominal, uma linearidade morfossintática hoje em dia caraterística do âmbito galego-português, embora noutras épocas atestada em mais línguas ou variedades românicas, como o ásture-leonês, o castelhano, o francês, o italiano ou o romeno (Sánchez Rei 2016: 152) e tradicionalmente sentida para o galego como positiva marca de estilo (Saco Arce 1868: 162-63; Freixeiro Mato 2013: 382; etc.). No caso do 
Os pronomes pessoais e a expressão do objeto indireto no galego-português medieval e no galego contemporâneo: aproximação contrastiva

terceira estruturação, os pronomes podem ocorrer com adjacência (5a, 5c-d) ou sem adjacência (5b, 5e) (cf. Martins 2013: 2238):

(5) a. nõ au[er]emos bon tempo ata que lle a ela praza ende (CT: 286, 1373)

b. Et quando me estes estraños andan a mĩ tã sen arte, teño que moyto mays o deuedes vós facer (CT: 335, 1373)

c. Et segundo me a mĩ semella, tempo era de folgar (CT: 410, 1373)

d. A rem que mh-a mi mays valer / devya contra mha senhor / essa mi faz a mi peyor serviçc' (LP, I: 115, finais do s. XIII)

e. e ali me lançaron a min a falcatrua (LP, I: 124, c. 1284-1289)

\subsubsection{Estrutura 4: $\mathrm{V}+a+\mathrm{FN}$}

$\mathrm{Na}$ quarta modalidade não se deteta pleonasmo e aparece uma preposição $a$ que preludia a FN realizada lexicalmente sem a ocorrência do $\mathrm{Cl}$. Pela sua grande frequência nos textos, podemos considerá-la muito comum, contrariamente ao que acontece no galego atual (cf. 4.2.4):

(6) a. tomou hũa vaca a hũa vella viuba que tiina oito fillos (CSI: 64, c. 1468)

b. Et escripveu ao santo padre [...]. Et o papa escripveu a el rei por suas leteras [...]. Et aqui poden veer fermosas leteras et de boa rectorica, que o papa escripvia a el rei et à clerezia do reino (CSI: 80-81, c. 1468)

c. et despois de comer declarou ao abbade a causa da sua ida a Roma (CSI: 83, c. 1468)

d. et sse alguẽ uéér cõtra esta carta per britar pecti áá parte du rei.c. Morabitinos e ao querelãte.x. Morabitinos (DGP: 114-15, 1259)

e. em cujo lugar odeu Deus a seu padre Adam (GE: 25, $1^{\mathrm{a}}$ metade do s. XIV)

f. Item aforã a Martin Fernandez, clerigo de Senorim, et quatro uoses as vinas (HGP: 175, 1473)

g. E ao demo vou encomendar / prez deste mundo e armas de lidar (LP, I: 145, $2^{\mathrm{a}}$ metade do s. XIII)

h. Et quando o diserõ a Calrros, volueuse a França (MS: 98, $1^{\circ}$ quartel do s. $\mathrm{XV})$

i. et cõprou aos outros herdeiros toda a sua parte (MS: 59, $1^{\circ}$ quartel do s. XV)

\subsubsection{Estrutura 5: $\mathrm{V}+\mathrm{Cl}+a+\mathrm{FN}$}

Já na quinta construção se atesta a presença do $\mathrm{Cl}$ com $\mathrm{FN}$ introduzida por $a$ e explicitada lexicalmente. Corresponde a uma estrutura com muita menos documentação do que a anterior, situação que também se podia verificar para outras línguas e variedades românicas ${ }^{17}$ :

português, a interpolação é hoje em dia percebida geralmente como um traço sintático dialetal, próprio "da sintaxe medieval, mas que deixou de ser" usado no padrão, conforme expõe Segura (2013: 133).

17 Cf., por exemplo, Gómez Seibane (2013: 80), que assinala um comportamento parecido para as falas castelhanas do século XV. 
(7) a. et o queria tirar a el rei et darllo aos ingreses e normanos (CSI: 73, c. 1468)

b. Deus dalle vida escarnida ao que sse deserda cõ sua mão (CT: 249, 1373)

c. Santiago que se nõ nega aos que o demandã cõ boo coraçõ et que lles acorre aas coytas moy çedo (MS: 195, $1^{\circ}$ quartel do s. XV)

\subsubsection{Estrutura 6: $\mathrm{V}+\mathrm{Cl}$}

$\mathrm{Na}$ última das possibilidades aparece unicamente o $\mathrm{Cl}$, em cujo caso se encarrega de desempenhar uma verdadeira função sintática. Esta construção apresenta um traço caraterístico a respeito das anteriores, sobretudo se comparada com a terceira $(\mathrm{V}+\mathrm{Cl}+a$ + obl. tónico), já que no caso dos dativos de P3 e P6 não é permitida a desambiguação do género (cf. Martins 2013: 2237):

(8) a. et doulles campanas moito bõas, et libros, et ornamentos (CSI: 87, c. 1468) b. Os bastardos partírõsse de aquel lugar hu lles Éytor auja mãdado que estouessen (CT: 340, 1373)

c. Et alý fezeron grãde ardimento et fezéronlles muy grã dãno (CT: 351, 1373)

d. Et leixarõ correr os caualos a ssy, et dérõsse tã grãdes feridas per çima dos escudos que tragíã que ja tã fortes nõ poderõ [...] seer que lles a fortaleza podesse prestar (CT: 371, 1373)

e. Pero a vejo, non lh'ouso dizer / a mui gran coita que me faz aver (UC, Nuno Rodríguez de Candarei)

f. pero davalle força que o cavaleiro con que se avia conbater que perderá muito do sangui (LTM: 103, $1^{\text {a }}$ metade do s. XIV)

g. Et esta estoria que oydes, vos cõtamos aquí (MS: $58,1^{\circ}$ quartel do s. XV)

\subsection{Alguns comentários}

As construções recolhidas nas seis epígrafes anteriores aproximam-nos de qual podia ser a situação do galego-português medieval no tocante à expressão do OI numa época que abrange vários séculos (XIII-XV). Com muita dose de verossimilhança, nesse tempo também teriam lugar flutuações e mudanças linguísticas motivadas por diferentes fatores de variação entre os sublinhados por Chambers et Trudgill (1994: 123-35, 138-81): contexto, estrato social, idade, geografia, sexo ou género, localização cronológica, etc., ainda que, na maior parte dos casos, se torne uma tarefa assaz complexa podermos desde a atualidade enveredar com satisfação esses tais fatores. Como dissemos anteriormente, os exemplos com que contamos são provenientes de textos escritos, alguns dotados de vontade artística (os literários ou não utilitários) e outros, contrastivamente, sem a procurarem (os utilitários, aqui representados pelos tabeliónicos). Entendemos, portanto, que um ponto de partida deve servir-nos para pensarmos que muito provavelmente a língua oral, embora coincidente numa boa parte com a escrita, não tinha de equivaler a esta com exatidão e que possuiria caraterísticas nem sempre atestáveis nos registos gráficos, também no que diz respeito às construções sintáticas vistas em 3.2. Voltamos a acu- 
Os pronomes pessoais e a expressão do objeto indireto no galego-português medieval e no galego contemporâneo: aproximação contrastiva

dir às impressões de López Martínez (1993: 223), que não descarta a possibilidade de a oralidade galaica dos séculos XIV e XV favorecer melhor que a escrita a presença de $a$ com as formas tónicas mim, $t i$, etc., isto é, as correspondentes à segunda estrutura ( $\mathrm{V}+a+$ obl. tónico).

Podemos reparar nalguns desses elementos de variação ponderados por Chambers e Trudgill. Partindo de fatores cronológicos, por exemplo, as construções recolhidas na quinta epígrafe $(\mathrm{V}+\mathrm{Cl}+a+\mathrm{FN})$ correspondem a uma estrutura que só começa a se detetar-se no outono da Idade Média, como os textos CT ou CSI (redigidos respetivamente em finais do século XIV e na segunda metade do s. XV), não se achando na poesia trovadoresca galego-portuguesa. Quanto a questões geolinguísticas, a CSI foi escrita na variedade local de Compostela, segundo o parecem verificar alguns fenómenos gramaticais registados ${ }^{18}$; isto pode explicar que nessa modalidade não houvesse determinados traços relativamente aos pronomes pessoais, que, talvez, se pudessem atestar noutras obras. Note-se, igualmente, como o tipo de composição parece ter inflacionado certas caraterísticas tipológicas: a primeira das estruturas $(\mathrm{V}+$ obl. tónico) aparece de preferência em textos literários e, dentro destes, na poesía (LP, UC), mas é escassa ou quase inexistente noutras obras (CT, LTM, etc.).

Mais um aspeto que temos de salientar é aquele relacionado com a causa de haver várias construções sintáticas para assinalarem o OI. Talvez uma primeira resposta, quiçá a mais lógica, assente no facto de se tratar de um sistema não totalmente fixado na altura, sobretudo ao pensarmos na existência da segunda e terceira das estruturas $(\mathrm{V}+a+$ obl. tónico, $\mathrm{V}+\mathrm{Cl}+a+$ obl. tónico $)$ ou na quarta e na quinta $(\mathrm{V}+a+\mathrm{FN}$, $\mathrm{V}+\mathrm{Cl}+a+\mathrm{FN}$ ), com as conseguintes oscilações próprias dessa situação. Se até hoje somos capazes de acharmos estruturas que constatam como esse sistema, mesmo estando num altíssimo grau de fixação, não enforma um modelo fortemente rígido (cf. Deu un beixo ao amigo Deulle un beixo ao amigo), torna-se lógico imaginarmos que na época medieval a situação era bem mais flutuável que na atualidade, o que parece verificar-se com a existência das seis tais possibilidades. Talvez um indício de isto assim ser possa vir pelo facto de atestarmos no mesmo texto, com apenas um pequeno trecho de distância, certas variantes combinatórias (primeira e segunda das estruturas em 9a, quinta e sexta em 9b):

(9) a. Et prometera ty et aos outros moytas boas cousas, et demais prometera a ti que a leue da igleia (MS: $65,1^{\circ}$ quartel do s. XV)

b. el rei Ordonio enviou ao papa grandes joias. O qual Genelo morou en corte do papa hũu ano et trouxo para aa dita eglleja de Santiago moitos libros et joias que lle enviou o papa ao obispo (CSI: 62, c. 1468)

18 Cf. a neutralização da VT em <e > na P2 do pretérito do indicativo dos verbos regulares e semirregulares da 3C (oieu e oeu, CSI: 56, 69, 71; fogeu, CSI: 71; parteuse, CSI: 67; etc.) ou a P3 dou (CSI: 89) do pretérito do indicativo do verbo dar. Uma notória parte destas variantes regionais pode ainda hoje ser verificada, como o demonstra o trabalho de Fernández Rei $(2003: 84,93)$. Para uma aproximação ao estado dialetal da Galiza da altura, veja-se Souto Cabo (1993) e Sánchez Rei (2011: 236-239, 390-395). 
Finalmente, no meio das seis estruturas e dessa sua presumível falta de fixação que acabamos de sublinhar, temos de assinalar que não achamos, quando menos nos textos utilizados, quaisquer exemplos de outras possíveis construções, do tipo $\mathrm{V}+\mathrm{Cl}+$ obl. tónico $(\operatorname{sem} a)$ ou $\mathrm{V}+\mathrm{Cl}+\mathrm{FN}$ (igualmente sem $a$ ).

\section{A situação da língua atual}

\subsection{As formas}

A deslocarmo-nos da Idade Média para o nosso tempo, começamos esta secção, tal e como se fez mais acima (cf. 3.1), recolhendo o conjunto de pronomes átonos que há na oralidade hodierna. Para este labor, tivemos em conta as descrições das gramáticas mais recentes (cf. Álvarez / Xove 2002: 534-539; Hermida Gulías 2004: 77, 82; Freixeiro Mato 2006, II: 122), secundarizando usos dialetais que não coincidem totalmente com as formas e as funções aqui expostas ${ }^{19}$ :

Tábua 2. Os pronomes pessoais átonos na língua atual

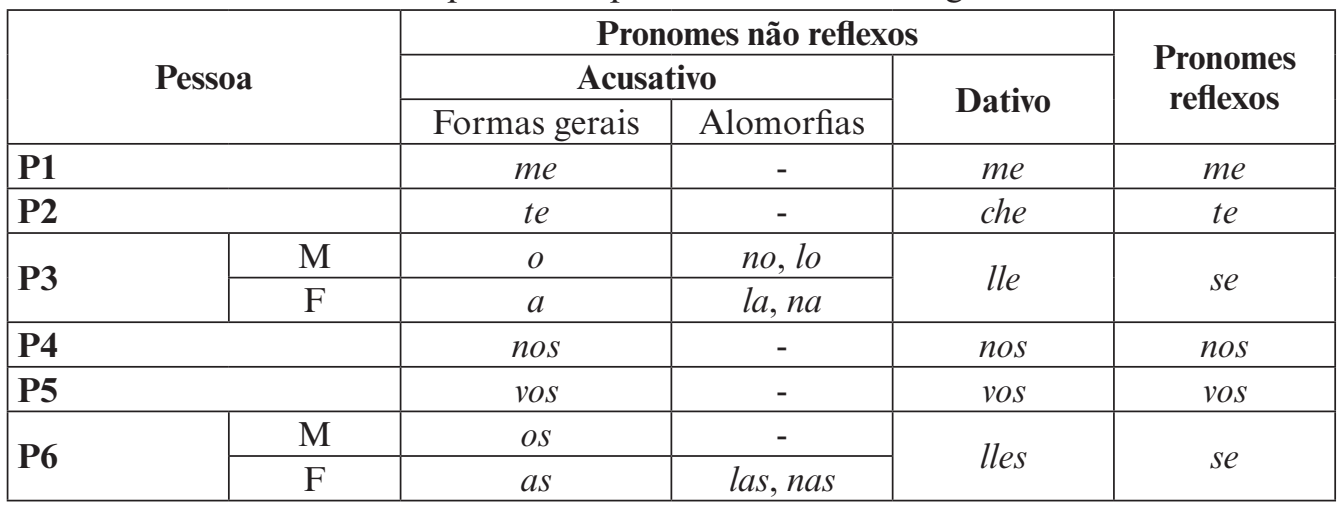

Da comparação deste quadro com o da língua medieval assinalado com anterioridade, evidenciam-se algumas questões de relevância. Em primeiro lugar, assiste-se a uma notável redução de variantes alomórficas e/ou alográficas, não se atestando na atualidade elementos tipicamente antigos como chi, xe, xi, etc., à exceção de em falares muito minoritários, como é o caso de chi, nus ou vus na comarca dos Ancares, registadas há uns anos por Fernández González (1981: 117), em cujo caso haveria que investigar se com efeito se trata de exemplos de conservadorismo linguístico ou, talvez mais provavelmente, de evoluções modernas. E em segundo lugar, dado que se tratava de simples variantes motivadas por fonética sintática ou combinatória, a tal míngua de formas não afetou no Galego a manutenção e desenvolvimento de funções dos clíticos (sintáticas ou pragmáticas) no passar da língua medieval à moderna.

19 Algumas já foram afloradas com anterioridade (cf. 3.2), como o uso universal de che para dativo e acusativo, próprio de algumas zonas, ou de te para ambas as funções, igualmente sujeito a distribuição geográfica. 
Os pronomes pessoais e a expressão do objeto indireto no galego-português medieval e no galego contemporâneo: aproximação contrastiva

\subsubsection{Estrutura 1: V + obl. tónico}

Vamos ver a seguir qual o comportamento atual e se se produziram mudanças sintáticas representativas. Indo à primeira das possibilidades, não achámos em nenhum texto oral qualquer exemplo desta construção, como também não encontrámos nas gramáticas galegas nenhuma referência a ela. Tampouco detetámos amostras no Galego Médio, o que, de um modo ou de outro, vem harmonizar com as impressões de López Martínez (1993: 221-24) e Monteagudo Romero (2019: 102-103) quando ponderavam que tais estruturas iam sendo cada vez mais raras a partir do século XIII.

A falta da partícula prepositiva é hoje possibilidade sentida como agramatical no galego e no PE. Contudo, como é sabido, no PB e ainda nos PALOP são vulgares os pronomes de P3 elelela e de P6 eleslelas a desenvolverem funções de OD (cf. Neves 2000: 457; Galves 2001; Azeredo 2008: 258; Silva 2013: 152; etc.). Na defesa da unidade linguística entre ambas as variedades de portugués, Melo (1981: 39), contrário àquelas pessoas que acreditavam na existência de uma "língua brasileira" autónoma a respeito do $\mathrm{PE}^{20}$, apelou precisamente às documentações antigas deste tipo de construções para assinalar que a presumível idiossincrasia brasileira bem podia provir, na realidade, do galego-português medieval:

Um exame consciencioso das divergências atuais entre o português do Brasil nos pantenteará, em primeiro lugar, que a maior parte dos fatos sintáticos brasileiros são apenas arcaísmos conservados. Assim, o pronome ele em função acusativo, a liberdade na colocação dos pronomes, a preposição em na regência de complementos dos verbos de movimento, o lhe como objeto direto, etc.

Por outro lado, os consabidos exemplos também de PB em que a forma tónica oblíqua de P1, mim, desempenha funções de SUJ (cf. Isso é muito caro para mim comprar), não podem ser aqui considerados precisamente por obedecerem a responsabilidades sintáticas diferentes (SUJ) com explicações diacrónicas igualmente diferenciadas (possível cruzamento de Isso é muito caro para eu comprar com Isso é muito caro para mim) ${ }^{21}$.

\subsubsection{Estrutura 2: $\mathrm{V}+a+$ obl. tónico}

Quanto à segunda possibilidade, já nos achamos numa situação não coincidente com exatidão com a anterior. Contrariamente à primeira estrutura, em obras do Galego Médio documenta-se muito ocasionalmente, até em ocasiões combinadas com outras construções (como en 10c):

20 Ainda que este sentimento já achasse alguns defensores em finais do século XIX, é nos tempos do Modernismo Brasileiro (1920-1940) que cobra uma especial força, nomeadamente com autores como Monteiro Lobato, Paulo Filho, etc.

21 A conversão de um pronome complemento em SUJ não se torna exclusiva do $\mathrm{PB}$, mas é comum a outras variedades linguísticas do âmbito galego-português. Assim, na metade ocidental da Galiza conseguiu-se habilitar o oblíquo ti como SUJ de P2 (Ti cantas, Ti cantabas, etc.), o que não foi desconhecido no português popular e dialetal (Coutinho 1976: 67, 161; Nunes 1989: 240): lembremos o citado exemplo do teatro vicentino Assi, ora vamos e ti / ó longo desta ribeira, proveniente do Auto da Feira, no qual o antigo advérbio assi exige a rima com $t i$. 
(10) a. A min chaman toda Mira / señora do gran tesouro (SEI: 15, finais do s. XV)

b. diga si vos debe a Patria / máis do que vós debés a ela (SEI: 32, 1697)

c. si el máis lle debe á cidade / ou Fonseca debe a ela (SEI: 50, 1697)

No que diz respeito à sua atestação em textos tradicionais da Galiza significativamente populares e dialetais, dispomos de algum exemplo esporádico (11a), embora, lamentavelmente, o oblíquo não desempenhe a função de OI, ficando assim à margem dos nossos interesses. Ao mesmo tempo, no português coloquial contemporâneo tal estrutura também não é totalmente desconhecida, quando menos nalguns textos orais de origem tradicional (11b-d), ainda que é criticada em gramáticas atuais (cf. Gonçalves / Raposo 2013: 1172, n. 27) ${ }^{22}$ :

(11) a. Chora meu pai que se mata; / que non tèn si non á min (CPG, III: 291)

b. -Não t'espantes, meu cavalo, não metas medo a mim (RT, I: 158)

c. - Tua mulher a mim chamou perra velha e a ti filho e mau pai (RT, I: 285)

d. -Não é nada, ó minha filha, a ti não importaria (RT, I: 740)

No tocante à oralidade galega atual, os textos disponibilizados em AGO e em ANF presenteiam só três $\operatorname{casos}^{23}$, o que dá indício da praticamente nula rendibilidade desta estrutura nos nossos dias. Desses três exemplos, ainda, temos de fazer algum comentário: em primeiro lugar, dois deles vão referidos à mesma pessoa e desenvolvem funções de OD, motivo este último que faz com que não os possamos considerar aquí; e em segundo lugar, nas três amostras percebe-se como sempre aparece P3, nunca se atestando outras formas pronominais:

(12) a. E despois el chegaba abaixo e apañaba, amarrábamo nunha rede e dicíame el: "Tira!" e eu tiraba para arriba e botábaos arriba os percebes, viráballe e despois amarráballe a rede na mesma corda e ía para abaixo outra vez; pero a rede inda ía ben, pero para subir a el para arriba! [...]. Para subir a el para arriba ata choraba. Dicía eu: "Papá, non subo [...], eu teño medo" (AGO, $112, \mathrm{Bueu}^{24}$ )

b. porque se ía tiña que lle pedir permiso, se non el non me deixaba ir, tiña que ir pedir permiso a el a ver se me deixaba ou non (AGO, 139, Compostela)

22 Note-se também a sua documentação em textos de proveniência tradicional ou popular a desenvolver a responsabilidade de OD: -Se a ele mandais matare, a mim mandai-me degolare (RT, I: 131); Que matasse a ti, mulher, que e p'ra casar co'a sua filha (RT, I: 241); Salva a mim, / a ti, / a todos quantos aqui estão (RT, I: 731); etc. Almeida (1999: 426), a este respeito, não se mostra contrário a tais estruturas: "Não devemos pensar que é errado dizer 'levei a ele', 'escolheu a nós' em vez de 'levei-o', 'escolheu-nos' [...]-O que não devemos é abusar dessa construção".

23 Temos constância de casos na linguagem infantil em que se verifica esta estrutura, normalmente em casos em que o pronome é de OD: "Mamá, pon bonita a min!", "Mamá, viste guapa a min". Agradecemos aqui a observação feita pela Profa. Dra. Maria Aldina Marques (Univ. do Minho), na qual fazia notar a presença de construções equivalentes nas crianças portuguesas.

24 Nos textos orais inclui-se a procedência geográfica, indicando o concelho. 
Os pronomes pessoais e a expressão do objeto indireto no galego-português medieval e no galego contemporâneo: aproximação contrastiva

\subsubsection{Estrutura 3: $\mathrm{V}+\mathrm{Cl}+a+$ obl. tónico}

A respeito da terceira construção, não se verifica qualquer mudança entre a época medieval e a moderna, à exceção, como é natural, do facto de ser na atualidade praticamente obrigatória a presença de $\mathrm{Cl}$ com o oblíquo tónico. Os séculos XVI-XVIII proporcionam amostras desta possibilidade (13a-b), ao passo que os corpora atuais de galego oral também a constatam com facilidade $(13 \mathrm{c}-\mathrm{g})$. Igual que acontecia na época medieval, pode haver exemplos com adjacência de formas pronominais (13a, 13c-d) ou sem ela $(13 b, 13 e)$ :

(13) a. Pois agora digo eu, / con perdon, si a min mo dan (SEI: 28, c. 1617)

b. porque / con voces moi desacordes / me ladras a min e mordes (CDE: 147, c. $1760-1777)$

c. era primo do home e díxome a min: "Non o despaches, nena, ese mozo non o despaches" (AGO, 139, Foz)

d. Dígoche a ti que facían rir a xente (AGO, 87, Lourenzá)

e. Mañá tócame cociñar a min, porquea miña nai non está (AGO, 122, Ribadavia)

f. E díxenlles a eles: "Facede a comida [...]"

g. moito gusto m’á min dan / as nenas do pelo roxo (CPG, I: 30)

Um aspeto deve ser ponderado relativamente à anterior possibilidade $(\mathrm{V}+a+\mathrm{obl}$. tónico), como é o caráter obrigatório na época atual do aparecimento dos $\mathrm{Cl}$ a acompanharem os oblíquos (cf. Faleiche / Faleiche a ti vs. *Falei a ti), o que não acontecia na língua medieval (cf. 3.2.2), mais tolerante em tais circunstâncias. Outrossim, parece pertinente indicarmos aqui que a língua oral, especialmente em registos marcados por uma forte coloquialidade, não é desconhecedora de outros tipos de pleonasmos com os pronomes pessoais como protagonistas. Estamos a referir-nos a reiterações de pronomes pessoais oblíquos, como o caso de (14a), em que figura duas vezes a forma tónica a nós (isto é, evidenciando uma amostra tanto de referenciação da pessoa gramatical quanto de estrutura de ênfase), ou segundo aparece em (14b), em que se adiciona un pronome coincidente na pessoa gramatical embora não coincidente no caso (nominativo em vez do oblíquo):

(14) a. Mira a nós que nos importan a nós os de Moraña nin a nación que os deu (AGO, 155, Teo)

b. Nós, a nós salvounos que despois non fomos á guerra (AGO, 23, Monforte de Lemos)

\subsubsection{Estrutura 4: $\mathrm{V}+a+\mathrm{FN}$}

Os dados de que se dispõe para a quarta possibilidade falam-nos com clareza no seu mais rentável uso na época medieval do que na atualidade. Na passagem dos séculos XVI-XVIII ao Galego Contemporâneo, no entanto, não deixa de se documentar, muito embora tenhamos de necessariamente partir de textos pouco numerosos: 
(15) a. E por esto deuxou esta ara a seus discípolos (HDS: 31, c. 1625-1635)

b. A essa cabeça do mundo / moito debeu Julio César (SEI: 29, 1697)

c. que o fillo á madre non debe / e esta a aquel debe a soldada (SEI: 49,1697)

e. Din que non quixen facer / nada aos ingreses que entraron (SEI: 107, 1697)

f. Botou-hos à gente, / rapaces è nenos $(\mathrm{C}: 216,1746)$

g. Eu nunca pensein / dar ao rey consellos (C: 325,1746$)$

h. se a dás a ler a outro, / acabouse a benquería (PG, I: 131, c. 1790)

Por sua vez, regista-se igualmente em vários exemplos contemporâneos tirados de poesias tradicionais, veiculadas em variedades de língua dialetais e populares:

(16) a. non debo carto a home / nin á muller d'esta terra (CPG, I: 50)

b. entreguéi o corazón / a quen non m'o merecía (CPG, I: 207)

c. non teño á quen dar as queixas / para dar ô meu rapás (CPG, III: 20-21)

d. O secreto d'o teu peito / Non contes ó teu amigo (LPG: 67)

e. Vou dicir a miña nai / Que andan as vacas n-a chousa (LPG: 99)

f. Unha vella dixo a outra / Polo burato d'a porta (LPG: 195)

Já no referente a casos provenientes da língua oral moderna, pudemos encontrar algumas amostras, apesar de, contrariamente às documentações da época medieval, não serem correntes; de facto, excetuando o caso de uma narração tradicional de caráter memorístico-recitativo, em que se repete uma destas estruturas em 8 ocasiões ${ }^{25}$, só achamos 10 exemplos desta quarta possibilidade nos corpora orais:

(17) a. viñan dous mozos e botaban así a man á túa man, e un bailaba con unha e outro bailaba con outra, e acabábase a peza e cada un ía polo seu lado (AGO, 136, Foz)

b. e era un home que non tiña medo a nada (ANF, Mazaricos)

c. Viñámos de volta; fomos leva-lo, o abrigo á, á tía Lucinda, viñamos de volta (ANF, Tomiño)

d. crean moito peligro ós barcos que estamos pescando, ló, que non é o primeiro caso de peligro de envestir outro (ANF, Ribeira)

e. E non ves que chama a atención á xente? (ANF, Vilalba)

f. coidamos o viño, levámolo ó anólogo pra que nolo cuide (ANF, Sober)

\subsubsection{Estrutura 5: $\mathrm{V}+\mathrm{Cl}+a+\mathrm{FN}$}

Conforme veremos a seguir, a quinta das construções corresponde à estrutura mais habitual na atualidade se confrontada com a anterior ( $\mathrm{V}+a+\mathrm{FN})$, o que contrasta com a situação na língua medieval, em que possuía muito poucas atestações (cf. 3.2.5). Quanto à sua génese, tanto $\mathrm{V}+\mathrm{Cl}+a+\mathrm{FN}$ como $\mathrm{V}+\mathrm{Cl}+a+$ obl. tónico foram

25 A expressão é "que fas/fai sombra ó sol” (ANF, Salvaterra de Miño). 
Os pronomes pessoais e a expressão do objeto indireto no galego-português medieval e no galego contemporâneo: aproximação contrastiva

no âmbito da romanística explicadas por motivos enfáticos ${ }^{26} \mathrm{e}$, muito possivelmente, a origem esteja numa inicial vontade de ênfase. Assim, a estrutura começaria por sublinhar a "prominencia de un elemento en relación al grado de topicidad" em contextos pragmaticamente marcados, como assinala Vivanco (2013: 232), situação que mudaria com o passar do tempo; a autora explica o seu progressivo sucesso no espanhol durante os séculos XVIII-XIX pelos seguintes termos:

A medida que se hace más frecuente, es decir, regular, la construcción pierde carga pragmática, de manera que hay un momento en el que el énfasis pragmático deja de ser un factor influyente sobre la duplicación. Es entonces cuando el hecho de que el clítico y el SN pleno comparezcan deja de resultar redundante y se vuelve regular.

Por seu turno, Gómez Seibane (2013: 80) indica que a partir do século XV se produz um importante aumento da duplicação de objetos no castelhano, ao passo que Eberenz (2000: 175, 179-80, n. 7) situa a regularização do redobro do clítico nesta língua já no século XVII, o que constituiu, a seu ver, um dos factos essenciais em que assenta a gramaticalização dos $\mathrm{Cl}$ como afixos verbais. Os motivos a que acode Eberenz para explicar essa mudança incluem, inicialmente, cinco: (i) as classes de elementos que aparecem no núcleo do complemento (pronome ou substantivo); (ii) o tipo de complementação argumental (OI ou OD); (iii) a situação do complemento relativamente ao verbo (anteposição ou posposição); (iv) a distância existente entre o complemento e o verbo; e (v) as classes de constituintes que se intercalam entre o verbo e o complemento; secundariamente, outros fatores, como a atualização do substantivo com determinante, a estrutura atancial do verbo ou os traços semânticos do complemento ([+/-humano]) também são tidos em consideração por Eberenz.

No tocante às documentações de $\mathrm{V}+\mathrm{Cl}+a+\mathrm{FN}$ no galego, já é de uso muito vulgar nos textos literários oitocentistas (cf. Freixeiro Mato et al. 2005: 325-26). Mesmo um autor como Saco Arce (1868: 166), sem dúvida o melhor gramático do século XIX e do primeiro quartel da seguinte centúria, já assinalava um uso quase geral. É nos séculos XVI-XVIII, pois, que a quinta das possibilidades foi ganhando terreno, pois em obras desse tempo já se atesta com relativa normalidade: proporcionalmente, tendo em conta a escassa literatura conservada do Galego Médio, este tipo de construções fica verificado por uma enorme quantidade de exemplos, muito maior que a correspondente à etapa medieval, também se achando com o OI antes do verbo (18a, 18d, 18e, 181) -o que favorece o redobro:

26 Note-se o dito por Iordan e Manoliu (1981, I: 285-290), que inclusive chegam a falar da oposição "enfático no enfático", expondo que as formas enfáticas "proceden habitualmente (salvo en portugués) de las formas conjuntas, a las que se añaden las formas absolutas". 
(18) a. que se ó rruyn non lle pon tacha / é mellor cós que alá sen (DAB: 280, c. 1595)

b. E foi que lles deron aos mestres un dos navíos (SEI: 100, 1605)

c. e de aquí lle veo muito dano ó Mariscal (SEI: 103, 1679)

d. à Afonso llo dixo / hum home jà vello (C: 147, 1746)

e. ouvira que á hum crego / llo estaba contando (C: 147, 1746)

f. Deixa que lle den / ao conde ó governo (C: 274, 1746)

g. pedíndolle ao cabaleiro / velas e diñeiro (CDE: 152, c. 1760-1777)

h. o dan dan non tocas / nin llo repicas aos probes (CDE: 161, c. 1760-1777)

i. repara as necesidades, / cúralle aos probes a tos (CDE: 164, c. 1760-1777)

h. qu'-ainda-en terra lhey de ter / med'-ó vento que respiro (RU: 26, 1777)

i. pidamoslh'ó Capitan, / que non dudo consigilo (RU: 32, 1777)

j. Ó carballo caille a folla (PG, I: 138, c. 1790)

1. O casado casa quer / ó solteiro non lla dan (PG, I: 144, c. 1794)

Um caso particular na documentação desta época do Galego Médio é o constituído pelos textos HDS e HSI. O responsável do primeiro tencionou, na primeira metade do século XVII, dar à língua um ar arcaizante para verificar a antiguidade da obra e assim legitimar uma linhagem familiar galaica, segundo pondera Souto Cabo (2007: 186); no entanto, no aspeto sintático as suas espetativas parecem ter ficado um pouco afastadas desse propósito, pois, como se verá mais abaixo, atesta-se o reforço com o clítico em contruções com FN, um traço escassamente registado na língua medieval. A segunda das obras, redigida entre os anos 1713 e 1737, é cópia de um códice medieval galego; a linguagem refletida nele pode considerar-se híbrida, pois o autor "modificou o texto do códice que manexaba ao introducir variantes fonéticas e morfolóxicas e mesmo algunha palabra, talvez coa intención de aproximar a lingua medieval ao galego do seu tempo" (Arias; Noia 2011: 68-69). Como quer que seja, junto à construção V + $a$ $+\mathrm{FN}$, documentam-se também exemplos de $\mathrm{V}+\mathrm{Cl}+a+\mathrm{FN}$ em ambos estes livros (particularmente em HSI), em ocasiões mesmo a alternarem com a anterior estrutura (19e-f); talvez, as circunstâncias singulares da redação de cada uma destas obras possam explicar a deteção das duas possibilidades, ao passo que também deixam a porta aberta à interpretação dessas documentações como devidas à transição entre os usos antigos e os contemporâneos:

(19) a. si non mandar algo, / que lle quiten o cambio a seu fillo (HDS: 89, c. 16251635)

b. onde predicara e se lle aparezera ás partes do occidente (HSI: 87, c. 17131737)

c. e este dixo a San Siluestre que respondeu o ataria (HSI: 94, c. 1713-1737)

d. mais a proue a Deus que viessen a concordia (HSI: 101, c. 1713-1737)

e. A Hermerico sucedeulle seu fillo Riquila (HSI: 102, c. 1713-1737)

f. A Rexiario sucedeu seu fillo Ariamiro (HSI: 107, c. 1713-1737)

g. Por ende o dito D. Afonso negou a o Mouro Molet o dito feudo (HSI: 129, c. 1713-1737) 
Os pronomes pessoais e a expressão do objeto indireto no galego-português medieval e no galego contemporâneo: aproximação contrastiva

h. deron a sua Ygreja moitos panos e joyas (HSI: 137, c. 1713-1737)

i. a o cal Papa imbioulle Sisnando vn capellan [...] e o rey Ordonio lle mandou por el a o Papa grandes joias, o cal Galeno [...] trouxo para a dita Ygreja de Santiago moitos libros e joias que lle imbiou o Papa a o Obispo (HSI: 144, c. 1713-1737)

No tocante ao sucesso da quinta estrutura no galego moderno, a nosso ver, confluem fundamentalmente fatores internos e externos. A respeito daqueles, em primeiro lugar, pensemos que a $\mathrm{V}+\mathrm{Cl}+a+\mathrm{FN}$ tinha relativa facilidade em se estender pelas estruturas transitivas da língua, pois contava com uma outra construção muito parecida $(\mathrm{V}+\mathrm{Cl}+a+$ obl. tónico), já abundantemente representada desde os primeiros textos medievais, a qual se manteve durante os séculos XVI-XVIII e conseguiu chegar até à atualidade. Em segundo lugar, como uma outra explicação ou caraterística interna, embora de menor alcance, também podemos acudir a possíveis necessidades de desambiguação das propriedades semânticas do OI, sobretudo em casos de elementos argumentais com o traço [+humano] (cf. Eberenz 2000: 180, n. 7):

(20) a. Sen o pretender, batinlle no pé (lle $=[+$ humano $]$ e $[$-animado $])$

b. Sen o pretender, batinlle no pé a ela $($ lle $=[+$ humano $])$

c. Sen o pretender, batínlle no pé á miña colega $(l l e=[+$ humano $])$

(21) a. Sen o pretender, batinlle no pé á mesa $(l l e=[$-animado $])$

b. ?Sen o pretender, batinlle no pé a ela (lle $=[$-animado $])$

E em terceiro lugar, a necessidade de desambiguar a adscrição genérica do elemento nominal do OI, possibilidade totalmente clara em $\mathrm{V}+\mathrm{Cl}+a+$ obl. tónico e ainda nalguma das restantes construções ( $\mathrm{V}+a+$ obl. tónico, $\mathrm{V}+a+\mathrm{FN}$, etc.), atrai a nossa olhada como mais uma hipótese interna para explicarmos o avanço de $\mathrm{V}+\mathrm{Cl}+a+$ FN; isto pode observar-se nas cláusulas (20b-c, 21a), em que não existe qualquer dúvida nessa identificação do género (ela, a miña colega, a mesa).

Vamos agora com os que se podem denominar fatores externos. Já vimos antes que é nos séculos XVII-XIX, segundo Eberenz, Gómez Seibane ou Vivanco, que estruturas como $\mathrm{V}+\mathrm{Cl}+a+\mathrm{FN}$ assentam definitivamente no espanhol e terminam por se fazer regulares nessa língua. Desde este estado de coisas, e com todas as cautelas precisas, não descartamos que a expansão de $\mathrm{V}+\mathrm{Cl}+a+\mathrm{FN}$, tendo em conta que já existia uma estrutura parecida $(\mathrm{V}+\mathrm{Cl}+a+$ obl. tónico $)$, pudesse ter-se visto potenciada pela sua correspondente consolidação no castelhano durante os séculos XVII-XIX. Esta provisória hipótese baseia-se noutras coincidências gramaticais que também seguiram parecidos passos na época do Galego Médio, sempre na linha da confluência com a na altura única língua oficial: note-se, assim, a redução da frequência da interpolação pronominal na oralidade (cf. Nunca che estiven eu alí, muito frequente, junto a Nunca che eu ali estiven, mais rara), o OD acompanhado desnecessariamente da preposição $a$ em casos em que não é de regra (cf. *Algúns cristiáns acomodados louvan a Deus, mais maltratan ás clases populares, em lugar de Algúns cristiáns acomodados louvan a Deus, 
mais maltratan as clases populares), a forte tendência à coincidência nas regências preposicionais (cf. aproximarse a e aproximarse de, contribuír a e contribuír para, facer que e facer con que...), etc.

A situação atual do PE para as atestações desta quinta possibilidade não coincide com o galego, pois em Portugal presentemente são muito minoritárias e mesmo as gramáticas costumam salientar a sua marginalidade ou até falta de validade: Cunha e Cintra (1992: 304), por exemplo, interpretam como "emprego enfático" a possibilidade de o dativo "poder reiterar o objecto indirecto colocado no início da frase"27, ao passo que uma estrutura como $\mathrm{V}+\mathrm{Cl}+a+\mathrm{FN}$, em confronto, é considerada agramatical no trabalho de Mateus et al. (2003: 832) ou no de Gonçalves e Raposo (2013: 1179), onde se explica que não pode ser válida quando se achar dentro "do mesmo grupo prosódico", isto é, na mesma cláusula. No entanto, nalgum momento foram consideradas traços positivos de estilo ${ }^{28}$ e continuam a se detetar em registos não coincidentes com a variedade standardizada: tal é o caso das seguintes amostras, provenientes da literatura tradicional de Trás-os-Montes, nas quais nem se produz a disposição do OI ao início da cláusula, isto é, estaria dentro do mesmo grupo prosódico conforme Gonçalves e Raposo:

(22) a. Já lhe deixo vinte contos a essa feliz, desgraçada (RT, I: 50)

b. -Deixo-lho à besta da tua mãe, que bem mo há-de estimar (RT, I: 260)

c. -Que lhe fizeste ao teu vinho, que me fez tanto mal (RT, I: 391)

d. -A senhora i-Ana, senhora i-Ana, dê-le conselhos à filha (RT, I: 434) ${ }^{29}$

e. vai-lhe entregar esta carta ao meu pai, escrita pela mina mão (RT, I: 489)

f. vai-le ensinar o caminho ao ceguinho (RT, I: 564)

g. de pedir-lhe a filha à condesa, condesa não me quis dar (RT, I: 879)

h. Madalena lh'escreveu uma carta a Jesus Cristo (RT, I: 898)

Os fatores internos aludidos para o galego poderiam explicar a sua presença nestas utilizações não coincidentes com os usos mais comuns ou habituais. No português, ao não contar com o teto do castelhano, tais estruturas não progrediram na sintaxe corrente. Como quer que seja, voltando à Galiza, tanto pelos fatores internos quanto pelos externos ou por uma combinação de ambos, $\mathrm{V}+\mathrm{Cl}+a+\mathrm{FN}$ possui hoje uma utilização largamente registada. A sua grande documentação no corpus oral verifica com absoluta clareza essa predominância caso comparássemos a quarta estrutura com a quinta: de um total de 207 exemplos, 10 amostras correspondem a V $+a+\mathrm{FN}$ e 197

27 Ambos os autores incluem como exemplos dois conhecidos provérbios portugueses: Ao pobre não lhe prometas e ao rico não lhe faltes e Ao médico e ao abade, diga-lhes sempre a verdade.

28 Tal é o caso da opinião de Francisco José Freire, que, a basear-se em textos do P. António Vieira (16081697), afirmava em finais do século XVIII -época em que a estrutura 5 avança no galego- que as tais construções, "longe de serem redundancias, são graças da indole da nossa lingua" (Freire 1842, parte $3^{\text {a }}$ : 123) (excerto citado também em Sánchez Rei 2008: 261).

$29 L e$, variante arcaica de lhe, foi forma muito comum na linguagem popular de certas regiões de Portugal, conforme verificou Vasconcellos nos primórdios do século XX $(1928,1981)$ : "Pour le datif, nous avons le partout, soit au singulier, soit au pluriel” (1981: 107). 
Os pronomes pessoais e a expressão do objeto indireto no galego-português medieval e no galego contemporâneo: aproximação contrastiva

a $\mathrm{V}+\mathrm{Cl}+a+\mathrm{FN}$ (isto é, percentualmente, $4,83 \%$ de $\mathrm{V}+a+\mathrm{FN}$ face a $95,16 \%$ de $\mathrm{V}$ $+\mathrm{Cl}+a+\mathrm{FN})$, das quais incluímos aqui algumas:

(23) a. había un chiste dun arrieiro que lles dicía ós seus fillos, cando ía morrer, dicí<a>, Que lles dicía "meus filliños, quérovos dicir unha cousa, que o viño tamén se fai de uva..." (AGO, 10, A Estrada)

b. ti pégaslle coa grande á pequena, que marche lonxe (AGO, 70, Compostela)

c. eu oía así falar, que..., oíallo sempre á defunta de miña avoa (AGO, 39, Mazaricos)

d. Á Luísa non lle dicimos porque..., como non..., é un pouquiño curta de vista, pois ó mellor cáenos por aí (AGO, 67, Xunqueira de Ambía)

e. E ós meus fillos iso pouco lles gusta. Ós fillos gústanlles os guisos (AGO, 120, Poio)

f. ós mariñeiros, e ós mariñeiros non lles dan nada (AGO, 130, Cariño)

\subsection{Estrutura 6: $\mathrm{V}+\mathrm{Cl}$}

Finalmente, a sexta possibilidade não apresenta problemas de continuidade documental entre a época medieval e a moderna, pois atesta-se tanto no galego-português da altura e nos textos do Galego Médio quanto na língua dos nossos dias. É nestes casos que o $\mathrm{Cl}$, na linha do já apontado, desenvolve uma verdadeira função sintática argumental, pois nele recaem as responsabilidades que, por causa de processos coesivos de flexibilidade textual, corresponderiam a uma FN lexicalmente realizada:

(24) a. E viñeron e puxéronlle pistolas e cercáronlle a casa con metralletas e unha chea de cousas desas, e colléronlle os cartos e non os deixaban mover (AGO, 6, Cabana)

b. hai que miralas e botarlles vitaminas e os pos que necesitan, volverlles xuntar a cría para que estea máis xunta e poidan criar máis. Despois hai que lles ir poñendo alzas (AGO, 131, Taramundi)

c. se ía tiña que lle pedir permiso, se non el non me deixaba ir, tiña que ir a pedir permiso a el a ver se me deixaba ou non (AGO, 139, Santiago de Compostela)

\section{Terminando}

Os exemplos que fomos expondo indicam-nos que, se confrontada a situação do Galego Medieval com a contemporânea, a expressão do OI se manteve em termos gerais, o que corrobora um sistema relativamente estável. Porém, uma análise mais pormenorizada revelar-nos-á que houve mudanças tanto nas formas clíticas documentadas na altura quanto nas construções que desenvolvem a função de OI. Assim, temos de deixar constância das seguintes alterações: (i) reduziu-se o número 
de variantes alográficas e/ou alomórficas ( $m i, x e, x i$, etc.); (ii) minguou também o número de estruturas, não se atestando hoje em dia no galego oral algumas, como a primeira ou a segunda $(\mathrm{V}+$ obl. tónico, $\mathrm{V}+a+$ obl. tónico), à exceção de variedades linguísticas muito marcadas e minoritárias (linguagem infantil, falares dialetais, etc.); (iii) em contrapartida, constata-se a normal manutenção através do tempo de outras estruturas, qual é o caso da terceira ou da sexta $(\mathrm{V}+a+$ obl. tónico, $\mathrm{V}+\mathrm{Cl})$; (iv) atesta-se a mudança do caráter marginal nos textos medievais para se converter, nos nossos dias, numa construção com uma grande presença, tal como se produziu com a quinta $(\mathrm{V}+\mathrm{Cl}+a+\mathrm{FN})$; e (v) verifica-se uma notabilíssima mudança na frequência de aparecimento, conforme se deu com a quinta das estruturas ( $\mathrm{V}+\mathrm{Cl}+a+\mathrm{FN})$, a qual, embora legítima, é dificilmente registável na atualidade. A tábua seguinte sintetiza a situação da língua medieval e a do galego atual no tocante às possibilidades de construção sintática:

Tábua 3. As seis possibilidades na língua medieval e na moderna

\begin{tabular}{|l|l|c|c|}
\hline \multicolumn{2}{|l|}{} & Idade Média & Época atual \\
\hline Estrutura 1 & $\mathrm{V}+$ obl. tónico & + & - \\
\hline Estrutura 2 & $\mathrm{V}+a+$ obl. tónico & + & $(-)$ \\
\hline Estrutura 3 & $\mathrm{V}+\mathrm{Cl}+a+$ obl. tónico & + & + \\
\hline Estrutura 4 & $\mathrm{V}+a+\mathrm{FN}$ & + & $(+)$ \\
\hline Estrutura 5 & $\mathrm{V}+\mathrm{Cl}+a+\mathrm{FN}$ & $(+)$ & + \\
\hline Estrutura 6 & $\mathrm{V}+\mathrm{Cl}$ & + & + \\
\hline
\end{tabular}

Como foi assinalado com anterioridade, partimos do facto de o $\mathrm{Cl}$ ser na verdade um morfema verbal que, em ocasiões, desenvolve funções argumentais centrais, uma delas a de OI. Precisamente, o modo de esta aparecer na língua medieval e na moderna e os seus vínculos com a manifestação da concordância entre o verbo e os seus complementos também experimentaram algumas transformações. Na tábua a seguir mostra-se como a emergência e posterior consolidação de $\mathrm{V}+\mathrm{Cl}+a+\mathrm{FN}$ no Galego Médio envolveu uma outra construção em que a manifestação da concordância entre o verbo e o OI se converteu no aspeto gramatical mais relevante, enquanto se vê como a tal concordância é quase inversamente proporcional à expressão da função sintática através dos pronomes átonos:

Tábua 4. Expressão da concordância e da função sintática na Idade Media e no Galego Atual

\begin{tabular}{|l|l|c|c|}
\hline \multicolumn{2}{|l|}{} & $\begin{array}{c}\text { Concordância } \\
\text { do V com os Cl }\end{array}$ & Função sintática nos Cl \\
\hline Estrutura 1 & $\mathrm{V}+$ obl. tónico & - & + \\
\hline Estrutura 2 & $\mathrm{V}+a+$ obl. tónico & - & + \\
\hline Estrutura 3 & $\mathrm{V}+\mathrm{Cl}+a+$ obl. tónico & + & - \\
\hline Estrutura 4 & $\mathrm{V}+a+\mathrm{FN}$ & - & - \\
\hline Estrutura 5 & $\mathrm{V}+\mathrm{Cl}+a+\mathrm{FN}$ & + & - \\
\hline Estrutura 6 & $\mathrm{V}+\mathrm{Cl}$ & - & + \\
\hline
\end{tabular}


A concordância leva-nos a comentar a identificação do género gramatical do elemento que desenvolve a função de OI nas seis estruturas. Em maior ou em menor medida, todas elas facilitam sabermos a que género se pode adscrever o OI, exceto a última delas $(\mathrm{V}+\mathrm{Cl})$, a qual se torna totalmente opaca: nem uma frase nominal, nem uma estrutura de redobro do $\mathrm{Cl}$ possibilita, neste último caso, sabermos a que género associarmos o OI, o que não se produz com as cinco restantes:

Tábua 5. Identificação do género com $\mathrm{P} 3$ e P6

\begin{tabular}{|l|l|c|}
\hline Estrutura 1 & $\mathrm{V}+$ obl. tónico & + \\
\hline Estrutura 2 & $\mathrm{V}+a+$ obl. tónico & + \\
\hline Estrutura 3 & $\mathrm{V}+\mathrm{Cl}+a+$ obl. tónico & + \\
\hline Estrutura 4 & $\mathrm{V}+a+\mathrm{FN}$ & + \\
\hline Estrutura 5 & $\mathrm{V}+\mathrm{Cl}+a+\mathrm{FN}$ & + \\
\hline Estrutura 6 & $\mathrm{V}+\mathrm{Cl}$ & - \\
\hline
\end{tabular}

A combinarmos os tipos de manifestação do OI no galego atual vistos nas seis estruturas, observamos que existem vários modelos, nos quais convivem sistemas que podemos entender de duas maneiras: (i) não combinados, pois na frase só ocorre categorialmente uma classe de palavras, isto é, pronominais ou lexicais; e (ii) combinados, em que achamos pronomes pessoais vinculados a nomes (cf. Dállelo aos teus amigos) ou com outras subclasses de pronomes, como os demonstrativos, quantificadores, etc. (cf. Dállelo a aqueles amigos, Dállelo a aqueles, etc.). A viagem da língua medieval à moderna, com a transição dos séculos do Galego Médio, deixa ver como os primeiros modelos viram minguado o seu número e/ou a sua atestação $(\mathrm{V}+a+\mathrm{FN})$, ao passo que os segundos conheceram um notório e crescente sucesso:

Tábua 6. Modelos de estruturas para a expressão da função sintática

\begin{tabular}{|c|c|c|}
\hline \multicolumn{2}{|c|}{ Não combinados } & Combinados \\
\hline Pronominais & Lexicais & \\
\hline$(\mathrm{V}+a+$ obl. tónico $) \mathrm{V}+a+\mathrm{FN}, \mathrm{V}+\mathrm{Cl}$ & $(\mathrm{V}+a+\mathrm{FN})$ & $\mathrm{V}+\mathrm{Cl}+a+\mathrm{FN}$ \\
\hline
\end{tabular}

Por outro lado, um assunto à parte, que terá de ficar para ulteriores pesquisas no galego consistirá em aprofundarmos em temáticas já mais particulares, como, por exemplo, se o tipo de verbos quanto aos seus traços transitivos (bivalentes, trivalentes ou de valência variável) é capaz de verificar com maior facilidade uma estrutura não combinada $(\mathrm{V}+a+\mathrm{FN})$ ou combinada $(\mathrm{V}+\mathrm{Cl}+a+\mathrm{FN})$; se a frequência na linguagem normal de alguns verbos com esferas semânticas parcialmente coincidentes (como acontece, por exemplo, com os chamados "verbos de transferência": dar, doar, emprestar, oferecer, outorgar, proporcionar, presentear, transferir...; com os "verbos diretivos": exigir, pedir, propor, rogar, suplicar...; etc.) constata melhor uma ou outra construção $(\mathrm{V}+a+\mathrm{FN}$ ou $\mathrm{V}+\mathrm{Cl}+a+\mathrm{FN})$; se as propriedades semânticas do $\mathrm{CI}$ (beneficiário, destinatário, origem, etc.) viram determinantes para uma maior constatação do redo- 
bro do $\mathrm{Cl}$; se o contexto e o registo linguístico é na realidade importante para favorecer uma possibilidade como $\mathrm{V}+\mathrm{Cl}+a+\mathrm{FN}$ - intuito que, provisoriamente, podemos considerar afirmativo; etc.

E, finalmente, uma questão também à parte, embora relacionada intimamente com o que acabamos de assinalar, será explicarmos com acerto o retrocesso da quarta estrutura e o enorme sucesso da quinta na língua atual, mudanças que tiveram lugar nos séculos do Galego Médio. Os poucos textos conservados deste período aconselham sermos cautelosos para a formulação de quaisquer teorias desses aconteceres. No entanto, sem querermos abandonar a larga via da prudência, não podemos deixar de enveredar o caminho que nos leva a pensarmos que o triunfo da quinta das possibilidades no galego atual está muito relacionada com a sua regularização no espanhol durante essa época (analogamente ao que sucedeu com outras fenomenologias gramaticais), o que se pôde ver coadjuvado com muito pela normal existência de estruturas parecidas $(\mathrm{V}+\mathrm{Cl}+a+$ obl. tónico $)$ ou por outras motivações internas.

\section{BIBLIOGRAFÍA}

ALGa = INSTITUTO DA LINGUA GALEGA (1995): Atlas Lingüístico Galego. Vol. II. Morfoloxía Non Verbal. A Coruña: Fundación Barrié de la Maza.

ALMEIDA, Napoleão Mendes de (1999) [s.d.]: Gramática Metódica da Língua Portuguesa. São Paulo: Saraiva.

ÁlVAREZ BLANCO, Rosario (1997): "O complemento de solidariedade: a complicidade entre os interlocutores", Benigno Fernández Salgado (ed.), Actas do IV Congreso Internacional de Estudios Galegos (Universidade de Oxford, 26-28 setembro 1994): 37-53. Oxford: Centre for Galician Studies,

ÁLVAREZ, Rosario (2015): "The accusative clitic in intransitive verb construction: ai o vai, aquí as están", Xulio Sousa et al. (eds.), Dialectologia. Special Issue V: 191-217.

ÁLVAREZ, Rosario; XOVE, Xosé (2002): Gramática da Lingua Galega. Vigo: Galaxia. ARIAS, Bieito; NOIA, Camiño (eds.) (2011): Pedro de Otero Romero y Torres, Historia da Igrexa de Iria. Vigo: Universidade de Vigo.

ARIZA, Manuel (2009): La Lengua del Siglo XIII (Dialectos Centrales). Madrid: Arco/Libros.

AZEREDO, José Carlos de (2008): Gramática Houaiss da Língua Portuguesa. São Paulo: Fundação Antônio Houaiss / Publifolha.

BOGARD, Sergio (2015): "Los clíticos pronominales del español: estructura y función”, Nueva Revista de Filología Hispánica. Vol. 63/1: 1-38.

BLINKENBERG, Andreas (1969) [1960]: Le Problème de la Transitivité en Français Moderne. Essai Syntactico-Sémantique, Historisk-filosofiske Meddelelser, udviget af Det Kongelige Dasnke Videnskabernes Selskab. Vol. 38, 1. Københvn: Munksgaard. 
Os pronomes pessoais e a expressão do objeto indireto no galego-português medieval e no galego contemporâneo: aproximação contrastiva

CARVAlHO, C. Almeida de (1953): Glossário das Poesias de Sá de Miranda. Lisboa: Centro de Estudos Filológicos.

CHAMBERS, Jack K.; TRUDGILL, Peter (1994): La Dialectología. Madrid: Visor.

CIDRÁS ESCÁNEO, Francisco Antonio (1992): "Sobre a función da concordancia. Consideracións a propósito das concordancias verbais anómalas", Verba. Vol. 19: 41-53.

COMPANY COMPANY, Concepción (2006): "El objeto indirecto", Concepción Company Company (dir.), Sintaxis Histórica de la Lengua Española. Vol. I. Primera Parte: La Frase Verbal: 477-572. México: Universidad Nacional de México / Fondo de Cultura Económica.

CORDIN, Patricia (1993): "Dative Clitic Doubling in Trentino", Syntactic Theory and the Dialects of Italy: 130-154. Torino: Rosenberg \& Sellier.

COUTINHO, Ismael de Lima (1976) [1938]: Gramática Histórica. Rio de Janeiro: Ao Livro Técnico.

CUNHA, Celso; CINTRA, Luís Filipe Lindley (1992) [1984]: Nova Gramática do Português Contemporâneo. Lisboa: Sá da Costa.

DUARTE, Inês Silva; MATOS, Gabriela Ardisson (1984): "Clíticos e sujeito nulo no português: contribuições para uma teoria de pro", Boletim de Filologia. Vol. 29: 479-538.

EBERENZ, Rolf (2000): El Español en el Otoño de la Edad Media. Sobre el Artículo y los Pronombres. Madrid: Gredos.

FERNÁNDEZ GONZÁLEZ, José Ramón (1981): El Habla de Ancares (León). Estudio Fonético, Morfosintáctico y Léxico. Oviedo: Universidad de Oviedo.

FERNÁNDEZ REI, Francisco (2003) [1990]: Dialectoloxía da Lingua Galega. Vigo: Xerais.

FERNÁNDEZ SORIANO, Olga (2000) [1999]: "El pronombre personal. Formas y distribuciones. Pronombres átonos y tónicos", Ignacio Bosque; Violeta Demonte (dirs.), Gramática Descriptiva de la Lengua Española. Vol. I: 1209-73. Madrid: Espasa.

FERREIRO, Manuel (1999) [1995]: Gramática Histórica Galega. Vol. I. Fonética e Morfosintaxe. Santiago de Compostela: Laiovento.

FREIRE, Francisco José (1842) [obra redigida no século XVIII]: Reflexões sobre a Lingua Portugueza. Lisboa: Sociedade Propagadora dos Conhecimentos Uteis.

FREIXEIRO MATO, Xosé Ramón (2006) [2000]: Gramática da Lingua Galega. Vol. II. Morfosintaxe. Vigo: A Nosa Terra.

(2013): Estilística da Lingua Galega. Vigo: Xerais.

FREIXEIRO MATO, Xosé Ramón et al. (2005): A Lingua Literaria Galega no Século $X I X$. A Coruña: Universidade da Coruña.

GALVES, Charlotte (2001): Ensaios sobre as Gramáticas do Português. Campinas: Universidade de Campinas.

GARCÍA-MIGUEL, José M. (1991): "La duplicación de complemento directo e indirecto como concordancia". Verba. Vol. 18: 375-410. 
GÓMEZ SEIBANE, S. (2013). Los Pronombres Átonos (le, la, lo) en el Español: Aproximación Histórica. Madrid: Arco/Libros.

GONÇALVES, Anabela; RAPOSO, Eduardo Buzaglo Paiva (2013): "Verbo e sintagma verbal", Eduardo Buzaglo Paiva Raposo et al. (orgs.): Gramática do Português. Vol. II: 1155-1218. Lisboa: Fundação Calouste Gulbenkian.

GONÇALVES, Rita (2015): "Romance languages do not have double objects: evidence from European Portuguese and Spanish". Estudos de Lingüística Galega. Vol. 7: 33-67.

HEGER, Klaus (1967): "La conjugación objetiva en castellano y en francés", Thesaurus. Boletín del Instituto Caro y Cuervo. Vol. 22/2: 153-175.

HERMIDA GULÍAS, Carme (2004): Gramática Práctica da Lingua Galega (Morfosintaxe). Santiago de Compostela: Sotelo Blanco.

HUBER, Joseph (1986): Gramática do Português Antigo. Lisboa: Fundação Calouste Gulbenkian.

IORDAN, Iorgu; MANOLIU, Maria (1989) [1972]: Manual de Lingüística Románica. Madrid: Gredos.

LÓPEZ MARTÍNEZ, María Sol (1993): O Complemento Directo con Preposición a en Galego. Anexo 36 de Verba. Santiago de Compostela: Universidade de Santiago de Compostela.

LUIS, Ana R; KAISER, Georg A. (2016): "Clitic pronouns", W. Leo Wetzels et al. (eds.), The Handbook of Portuguese Linguistics: 210-233. Hoboken-New Jersey: John Wiley \& Sons.

MARTINS, Nilce Sant'Anna (2000) [s.d.]: Introdução à Estilística. São Paulo: Queiroz. MARTINS, Ana Maria (2013): "Posição dos pronomes pessoais clíticos", Eduardo Buzaglo Paiva Raposo et al. (orgs.), Gramática do Português. Vol. II: 22292302. Lisboa: Fundação Calouste Gulbenkian.

MARIÑO PAZ, Ramón (2017): Fonética e Fonoloxía Históricas da Lingua Galega. Vigo: Xerais.

MATEUS, Maria Helena Mira et al. (2003): Gramática da Lingua Portuguesa. Lisboa: Caminho.

MELO, Gladstone Chaves de (1981) [1945]: A Língua do Brasil. Rio de Janeiro: Padrão. MIGUEL, Matilde et al. (2011): "Dativos não argumentais em português", Armanda Costa et al. (orgs.), Textos Seleccionados. XXVI Encontro da Associação Portuguesa de Lingüística: 388-400. Lisboa: Associação Portuguesa de Linguística.

MONTEAGUDO ROMERO, Henrique (2019): “Os pronomes ónicos oblicuos libres min e mí nos cancioneiros trobadorescos", Revista Galega de Filoloxía. Vol. 20: 91-118.

MORENO CABRERA, Juan Carlos (1987): Fundamentos de Sintaxis General. Madrid: Síntesis.

NEVES, Maria Helena de Moura (2000): Gramática de Usos do Português. São Paulo: Universidade Estadual de São Paulo. 
Os pronomes pessoais e a expressão do objeto indireto no galego-português medieval e no galego contemporâneo: aproximação contrastiva

NEVIS, Joel Ashmore et al. (1994): Clitics. A Comprehensive Bibligraphy (1892-1991). Amsterdam / Philadelphia: Jonh Benjamins.

NUNES, José Joaquim (1989) [1919]: Compêndio de Gramática Histórica Portuguesa. Lisboa: Livraria Clássica Editora.

OLIVEIRA, Fernão de (2000) [1536]: Gramática da Linguagem Portuguesa. Edição crítica, semidiplomática e anástica por Amaeu Torres e Carlos Assunção com um estudo introdutório do Prof. Eugenio Coseriu. Lisboa: Academia das Ciências de Lisboa.

PINEDA, Anna (2013): "Double object constructions in Spanish (and Catalan) revisited", Sergio Baauw et al. (eds.), Romance Languages and Linguistic Theory 2011: 193-216. Amsterdam / Philadelphia: John Benjamins.

PITA RUBIDO, Elsa (2006): "Algunhas consideracións sobre os dativos non argumentais", Revista Galega de Filoloxía. Vol. 7: 143-165.

POSNER, Rebecca (1998): Las Lenguas Romances. Madrid: Cátedra.

RAMOS, Maria Ana (2013): "Processos de reverência cultural? A adopção de $<1 \mathrm{~h}>$ e $<$ nh> na escrita portuguesa", Rosario Álvarez et al. (eds.), Ao Sabor do Texto. Estudos Dedicados a Ivo Castro: 481-514. Santiago de Compostela: Universidade de Santiago de Compostela.

RAPOSO, Eduardo Buzaglo Paiva (2013): "Pronomes", Eduardo Buzaglo Paiva Raposo et al. (orgs.), Gramática do Português. Vol. I: 883-916. Lisboa: Fundação Calouste Gulbenkian.

SACO ARCE, Juan Antonio (1868): Gramática Gallega. Lugo: Imprenta de Soto Freire.

SÁNCHEZ REI, Xosé Manuel (2008): “O português popular dos séculos XVI-XIX e a sua importância para o estudo do Galego Médio", Revue Romane. Vol. 43/2: 248-272.

(2011): Lingua Galega e Variación Dialectal. Santiago de Compostela: Laiovento.

(2016): "A interpolación pronominal no tránsito do galego medieval ao galego contemporáneo", Ramón Mariño Paz; Xavier Varela Barreiro (eds.), A Lingua Galega no Solpor Medieval: 147-178. Santiago de Compostela: Conse1lo da Cultura Galega.

SEGURA, Luísa (2013): "Variedades dialetais do português europeu", Eduardo Buzaglo Paiva Raposo et al. (orgs.), Gramática do Português. Vol. I: 83-142. Lisboa: Fundação Calouste Gulbenkian.

SPENCER, Andrew; LUÍS, Ana R. (2012): Clitics. An Introduction. Cambridge: Cambridge University Press.

SILVA, Rosa Virgínia Mattos e (1989): Estruturas Trecentistas. Lisboa: Imprensa Nacional-Casa da Moeda.

(2013): "O português do Brasil”, Eduardo Buzaglo Paiva Raposo et al. (orgs.), Gramática do Português. Vol. I: 45-154. Lisboa: Fundação Calouste Gulbenkian. 
SOUSA, Xulio (2012): "Esquemas causativos en galego, portugués europeo e portugués brasileiro", Xoán Lagares, Henrique Monteagudo (orgs.), Galego e Português Brasileiro: história, variação e mudança: 175-190. Niterói / Santiago de Compostela: Editora da Universidade Federal Fluminense / Universidade de Santiago de Compostela.

SOUTO CABO, José António (1993): "Caracterizaçom dialectal da Galiza da Idade Média", Gerold Hilty (ed.), Actes du XX Congrès International de Linguistique et Philologie Romanes. Vol. II: 531-545. Tübingen / Bassel: Francke.

(2007): "Estudo lingüístico", José António Souto Cabo (ed.), A História de Don Servando: 177-247. Sada-A Coruña: Ediciós do Castro.

VÄÄNÄNEN, Veikko (1988) [1968]: Introdución al Latín Vulgar. Madrid: Gredos.

VASCONCELLOS, José Leite de (1928): Opúsculos. Vol. II. Dialectologia (Parte I). Coimbra: Universidade de Coimbra.

(1981) [1901]: Esquisse d'une Dialectologie Portugaise. Lisboa: Instituto Nacional de Investigação Científica.

VILELA, Mário (1992): Gramática de Valências. Teoria e Aplicação. Coimbra: Livraria Almedina.

(1999) [1995]: Gramática da Língua Portuguesa. Coimbra: Livraria Almedina.

VIVANCO, Margot (2013): "La noción de tópico en la evolución de la duplicación clítica", Dicenda. Vol. 31: 229-249.

WANNER, Dieter (1987): The Development of Romanic Clitic Pronouns. From Latin to old Romance. Berlin / New York / Amsterdam: Mouton de Gruytier.

WILliAMS, Edwing B. (1975) [1961]: Do Latim ao Português. Rio de Janeiro: Tempo Brasileiro.

\section{PERFIL ACADÉMICO E PROFISSIONAL}

Xosé Manuel Sánchez Rei é professor titular na Área de Filologia Galega e Portuguesa da Universidade da Corunha. O seu âmbito de investigação abrange a gramática do galego atual, a variação linguística e a linguagem literária, temas sobre os quais tem dado a lume diversos trabalhos en publicações especializadas (Cadernos de Lingua, Diacrítica-Ciências da Linguagem, Estudos Galego-Brasileiros, LaborHistórico, MadryGal, Revista de Letras, Revista Galega de Filoloxía, Revue Romane, Rostocker Romanitische Arbeiten, Verba, etc.). Entre os seus livros salientam Se o vós por ben teverdes. A Interpolación Pronominal en Galego (1999, prémio Carvalho Calero 1998 de Investigação Linguística), O Fidalgo e o Teatro. Tres Textos Dramáticos de Ramón Otero Pedrayo (1999), Os Pronomes Demostrativos: do Latín ao Galego Contemporáneo (2002), A Lingua Literaria Galega no Século XIX (2005, em parceria com X. R. Freixeiro e G. Sanmartín), A Lingua Galega no Cancioneiro de Pérez Ballesteros (2006, finalista nos Prémios da Crítica da Galiza), O Complemento Preposicional en Galego (2010), Lingua Galega e Variación Dialectal (2011), O Falar das Fadas. Lingua, Música e Toponimia da Galiza (2016), Cantar na Coruña. Cancioneiro Coruñés dos Séculos XVIII 
Os pronomes pessoais e a expressão do objeto indireto no galego-português medieval e no galego contemporâneo: aproximação contrastiva

e XIX (2017), etc. Também se tem ocupado da edição de monográficos de temática filológica galego-portuguesa, como Aspectos da Toponimia Menor Coruñesa (2014, com E. Mosquera), Modelos de Lingua e Compromiso (2014), Novas Perspetivas Linguísticas no Espaço Galego-Português (2015, junto a M. A. Marques), As Ciências da Linguagem no Espaço Galego-Português. Diversidade e Convergência (2016, com M. A. Marques) ou Estudos Atuais de Linguística Galego-Portuguesa (2019, com M. A. Marques), etc. É, igualmente, o tradutor para o galego do Curso de Lingüística Xeral (2005) de Ferdinand de Saussure.

Fecha de recepción: 17/01/2020

Fecha de aceptación: 05/05/2020 